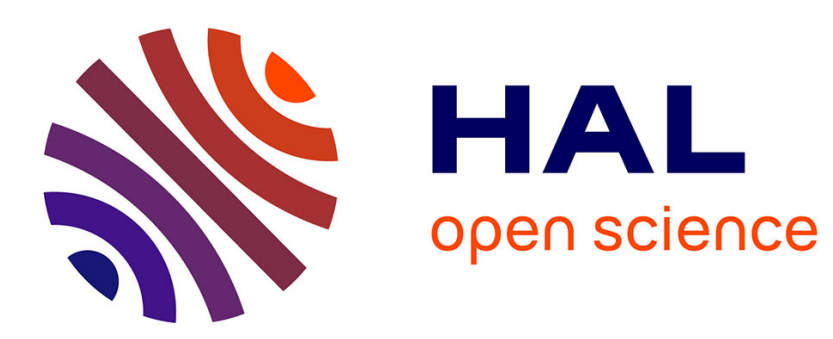

\title{
Attractive Marginality: Irish Painters in Brittany in the 1880s \\ Anne Goarzin
}

\section{To cite this version:}

Anne Goarzin. Attractive Marginality: Irish Painters in Brittany in the 1880s. Keatinge, Benjamin; Pierse, Mary. France and Ireland in the Public Imagination, Volume 55, Peter Lang, pp. 59-76, 2014, Reimagining Ireland Series. hal-01096155

\section{HAL Id: hal-01096155 https://hal.science/hal-01096155}

Submitted on 3 Jan 2015

HAL is a multi-disciplinary open access archive for the deposit and dissemination of scientific research documents, whether they are published or not. The documents may come from teaching and research institutions in France or abroad, or from public or private research centers.
L'archive ouverte pluridisciplinaire HAL, est destinée au dépôt et à la diffusion de documents scientifiques de niveau recherche, publiés ou non, émanant des établissements d'enseignement et de recherche français ou étrangers, des laboratoires publics ou privés. 

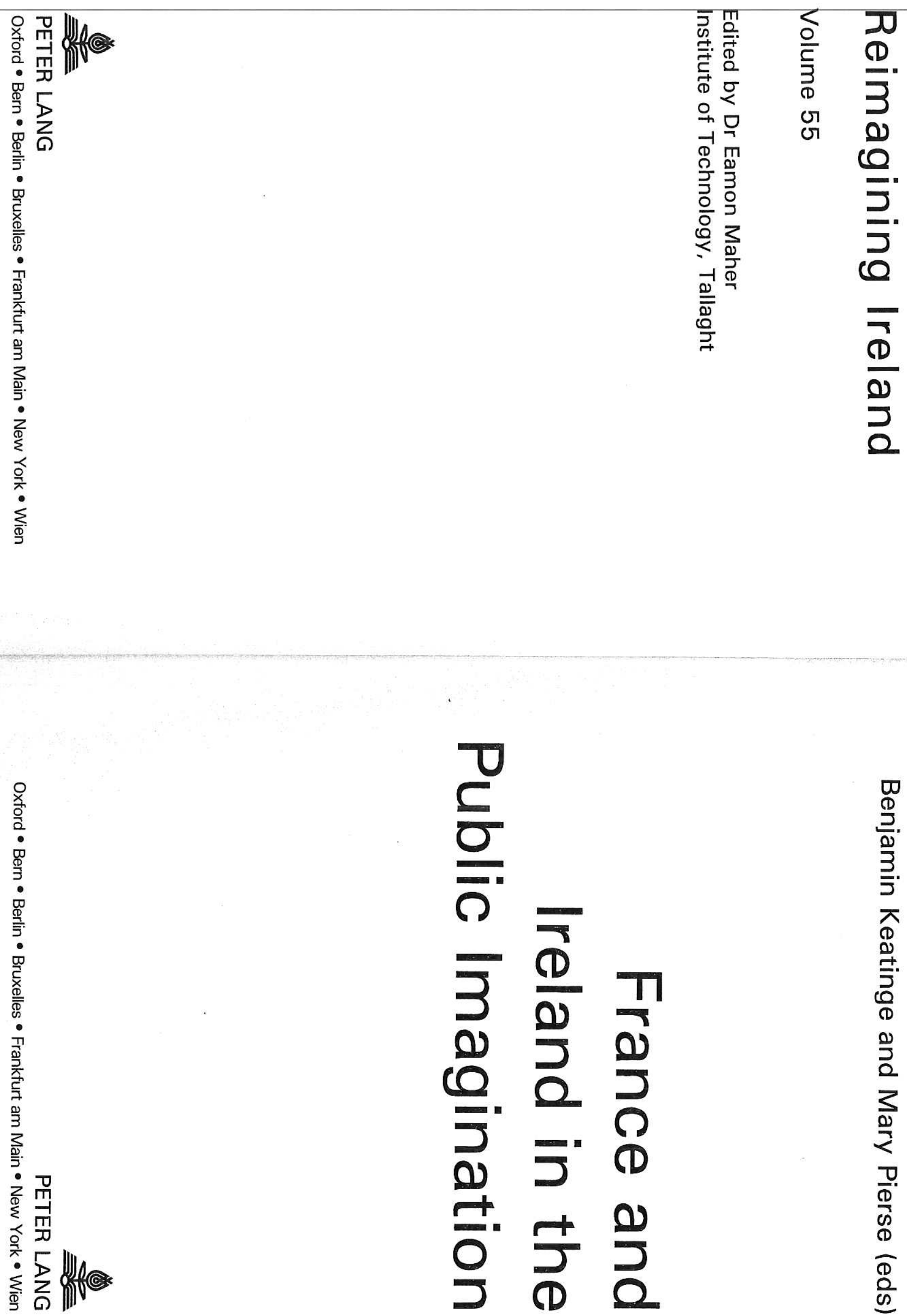


\section{Attractive Marginality: Irish Painters in Brittany in the 1880 s}

re, oral hisit possible ; did those nqualified $\mathrm{n}$ an ocean s s that bear innot be a stricted to is reduced sion is the elation to ld involve . constant ince must zculation.
Exhibitions of Breton-themed paintings by Irish artists sojourning in Brittany have taken place regularly over the last two decades, whether it is at the Pont-Aven Museum in $1999^{1}$ or at the Crawford Gallery of Art in Cork in $2000 .^{2}$ In September and October of 2010, Limerick's Hunt Museum mounted an exhibition entitled 'The French Connection ( $\&$ The Rediscovery of Thomas Hovenden).' It looks back on the influence of pleinairism and the contemporary taste for painting ordinary models, as well as reminding the viewer that towards the end of the nineteenth century, France attracted a considerable number of Irish (and international) artists whose works were very popular at the time. 'The French

I 'Peintres irlandais en Bretagne (1870-1930)', 26 June 1999-27 September 1999, see <http://www.museepontaven.fr/PEINTRES-IRLANDAIS-EN-BRETAGNE. html >. Accessed 15 October 2012.

2 'Irish Artists in Brittany', Crawford Municipal Art Gallery, Cork, 2000. An earlier exhibit was also devoted to Nathaniel Hill in 1993 ('Nathaniel Hill and the Bretons', Milmo-Penny Fine Art, December 2007).

3 'The French Connection', Io September-1o October 2010, Hunt Museum, Limerick. Online catalogue available at <http://www.adams.ie/clandeboye/documents/ FrenchConnectionCat-small.pdf $>$. Accessed 4 May 2012

4 In addition to the expected favourite painters such as Sir John Lavery, George Osborne, Charles Lamb or Nathaniel Hill, the zoro 'French Connection' exhibition at Adams sought to display works by lesser known figures such as Thomas Hovenden, a Cork-born artist who became famous in America in the 1880s, as well as Stanhope Forbes (who went on to create the Newlyn school of painting in Cornwall), Mary Kate Benson and Georgina Moutray Kyle. See the online catalogue, 3-4. <http:// www.adams.ie/clandeboye/documents/FrenchConnectionCat-small.pdf $>$. Accessed II July 2012. 


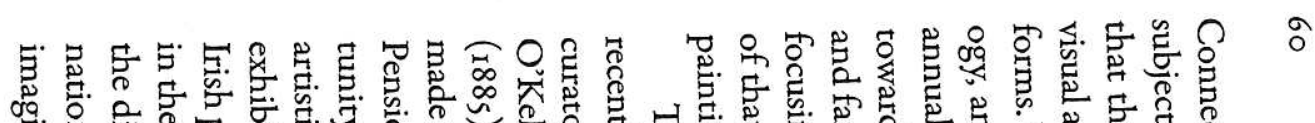

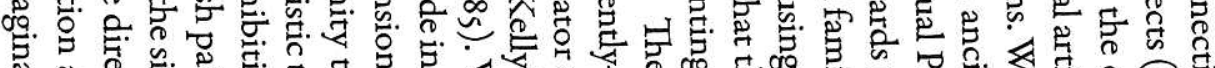

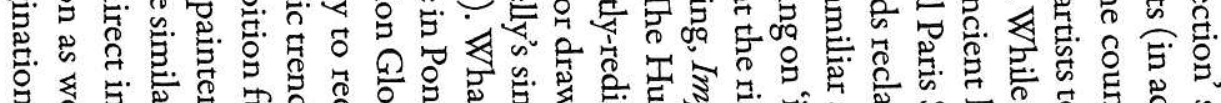

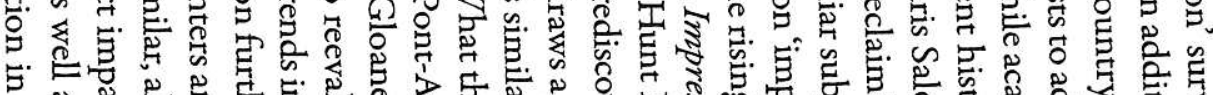

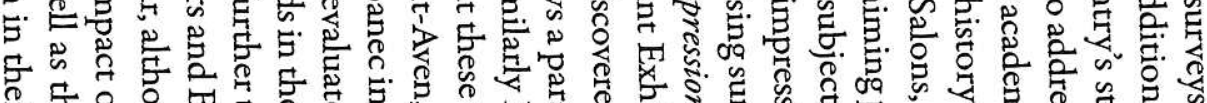

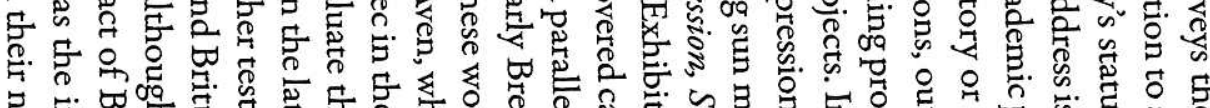

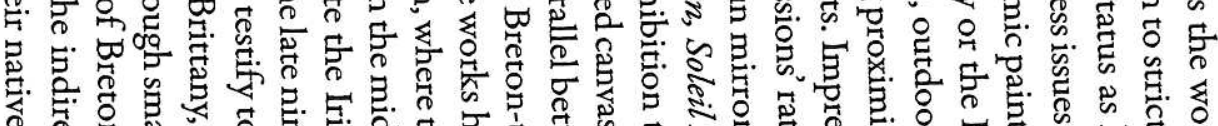

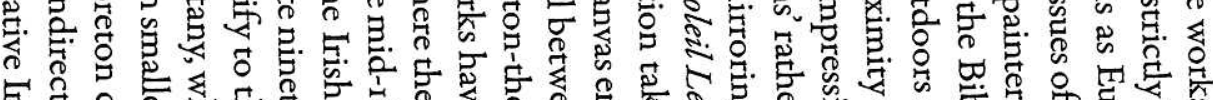

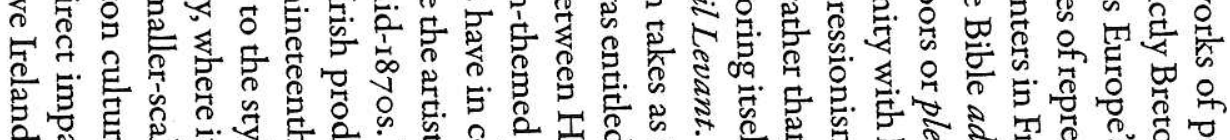

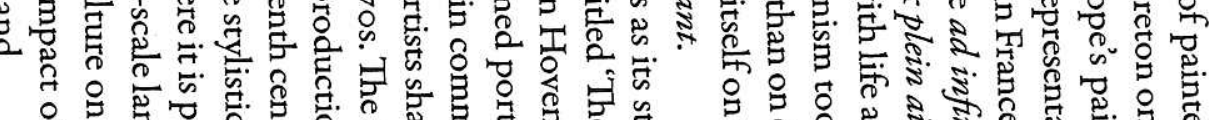
号递它

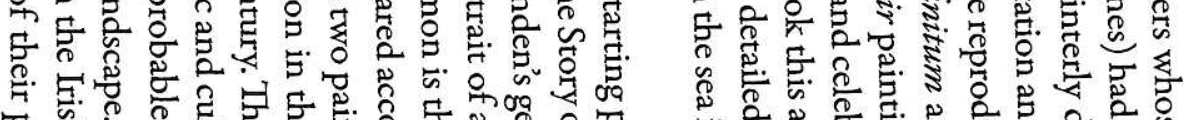

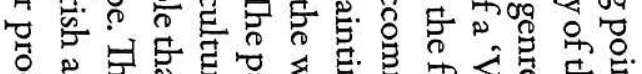

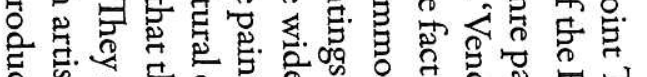

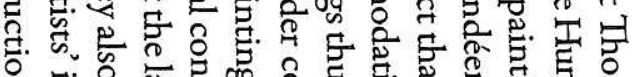

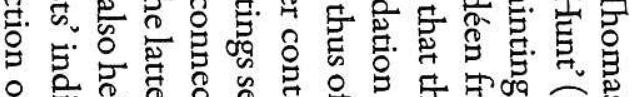

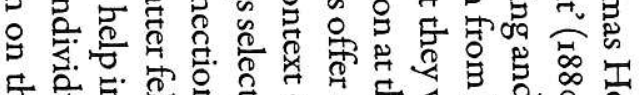

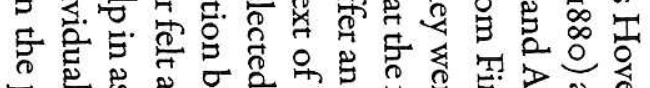

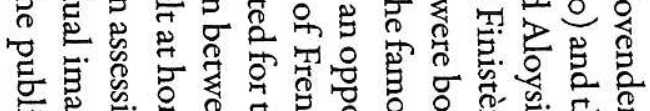

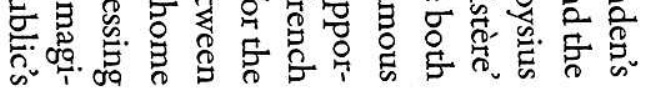

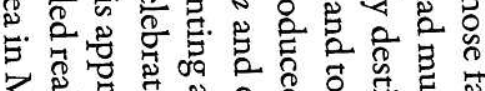

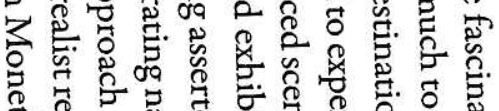

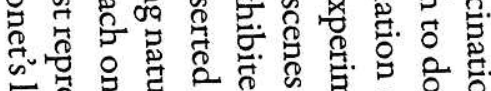

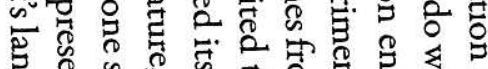

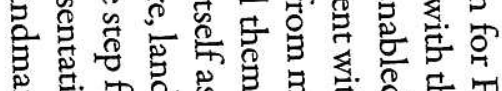

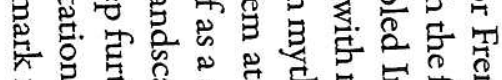

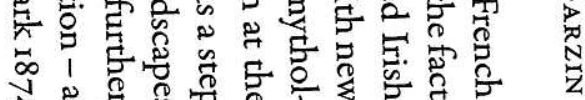

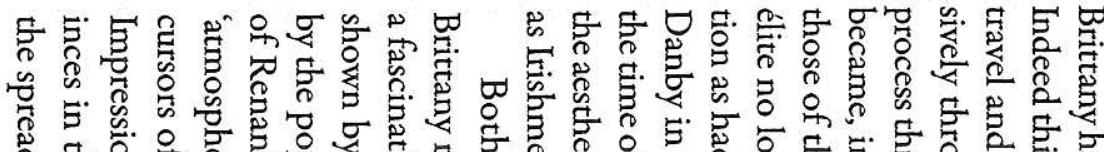

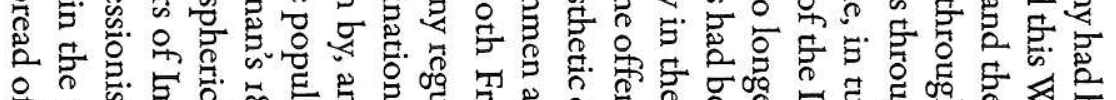

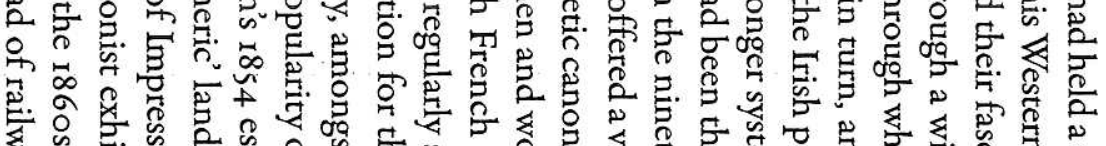

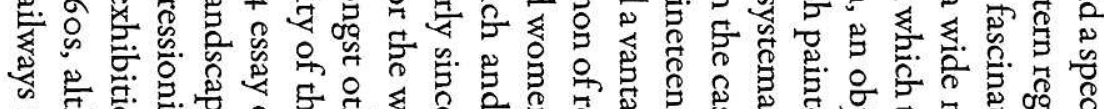

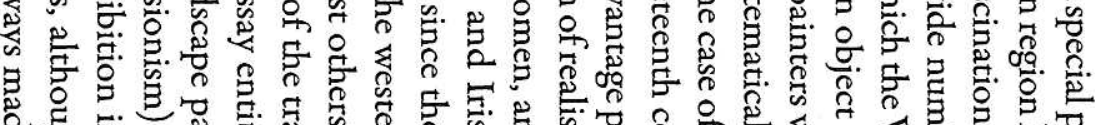

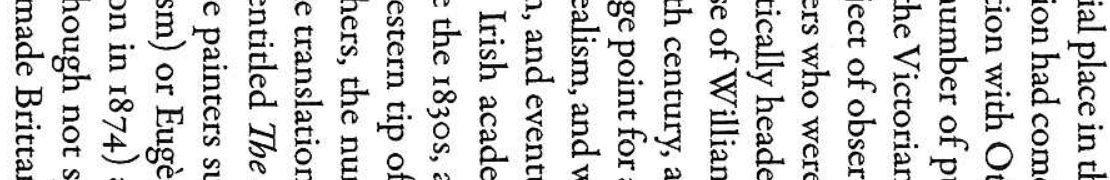

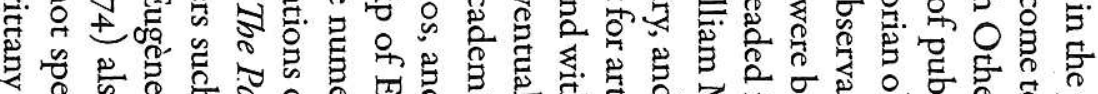

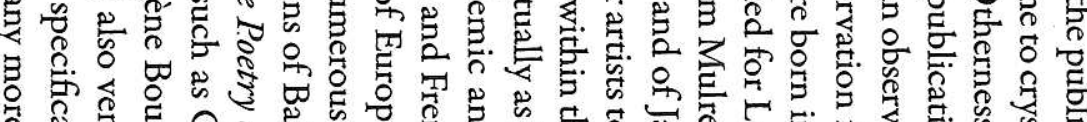

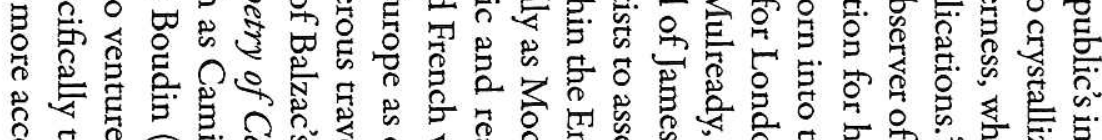

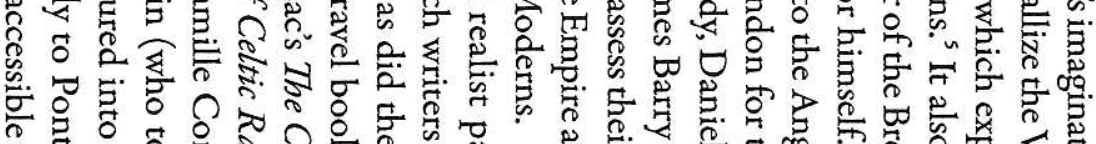

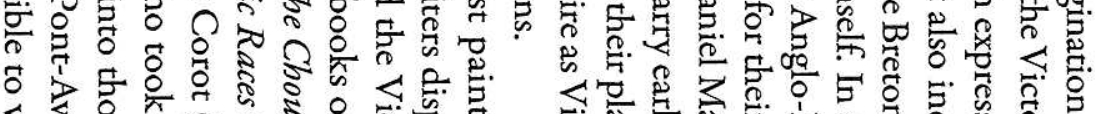

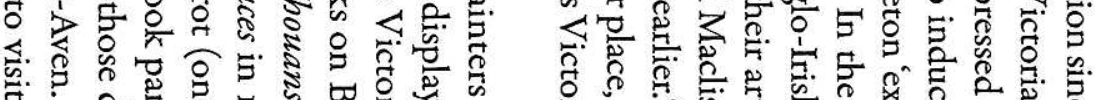

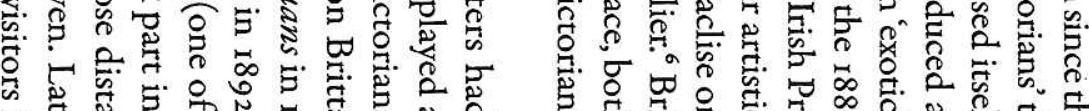

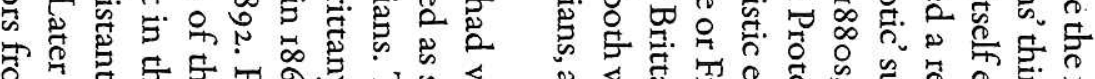

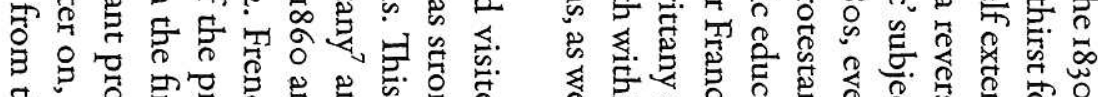

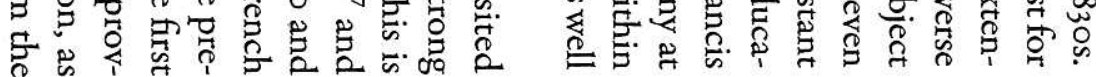




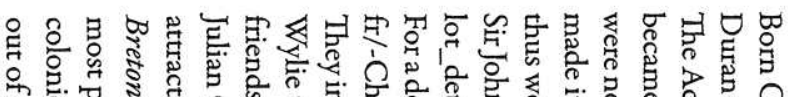

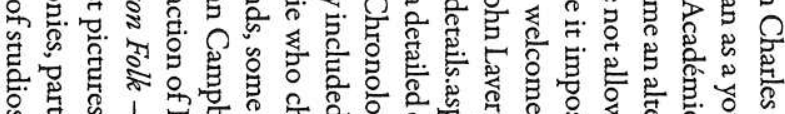

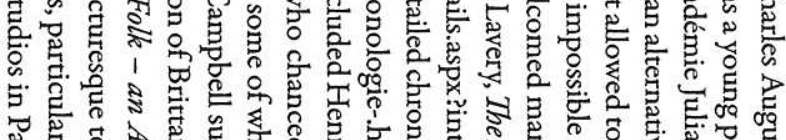

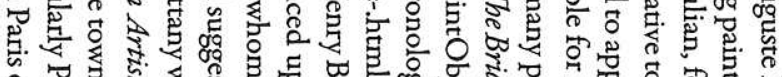

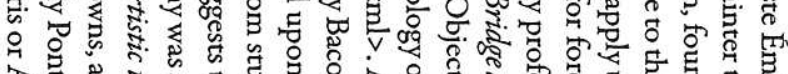

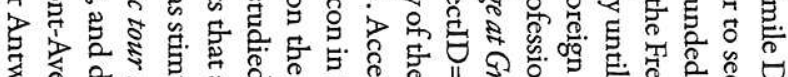

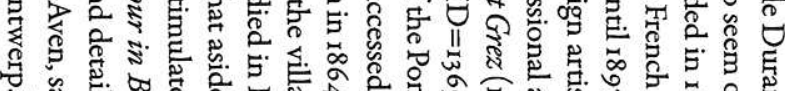

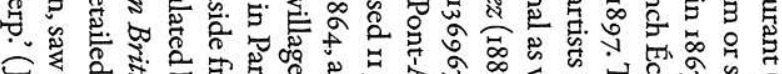

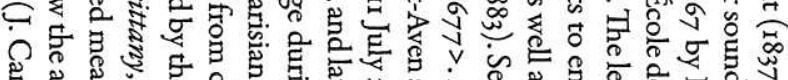

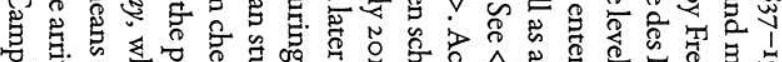

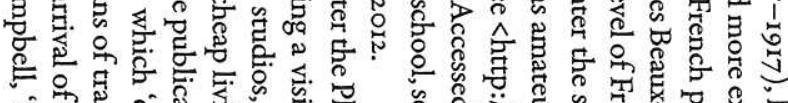

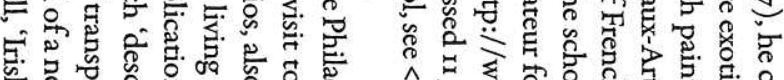

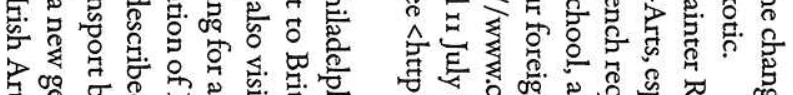

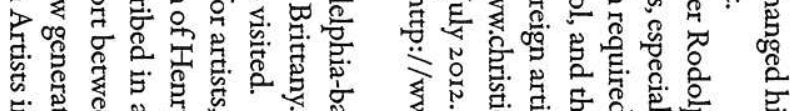

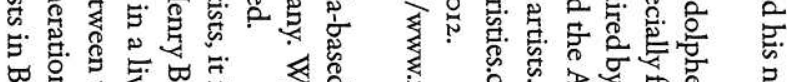

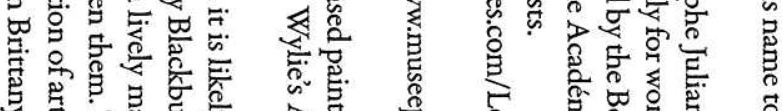

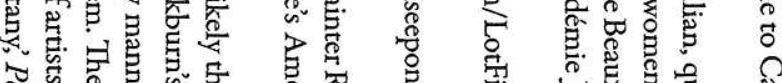

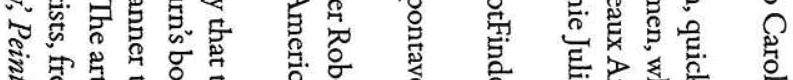

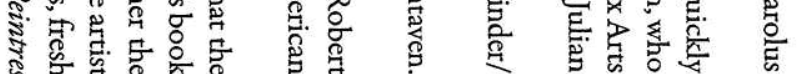

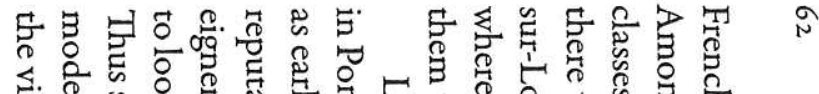

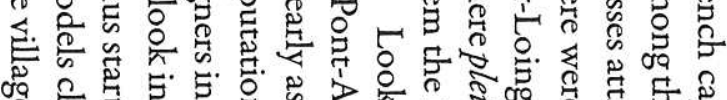
ơ

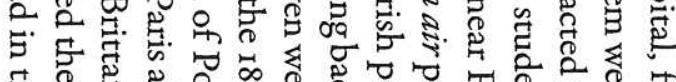

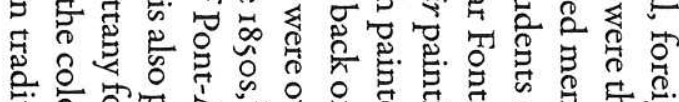

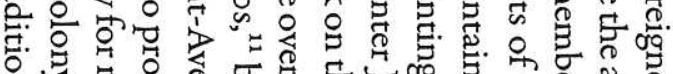

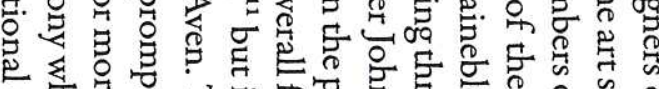

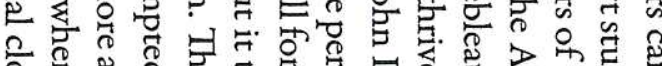

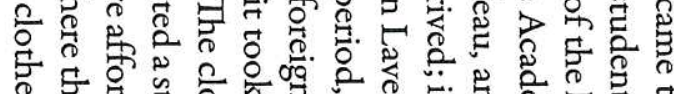

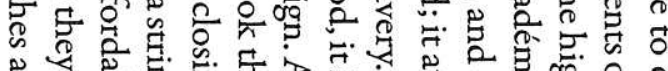

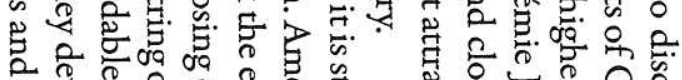

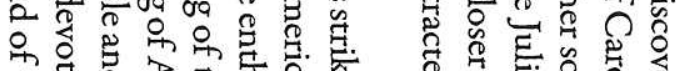

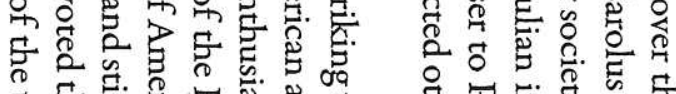

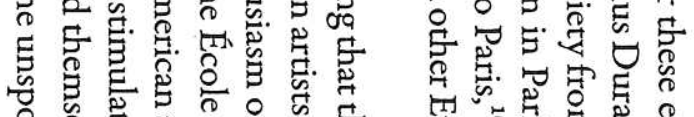

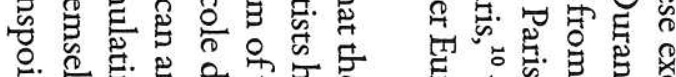

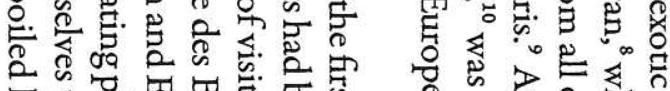

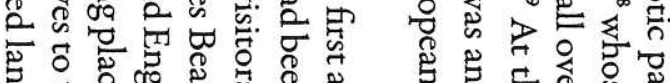

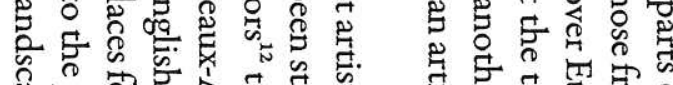

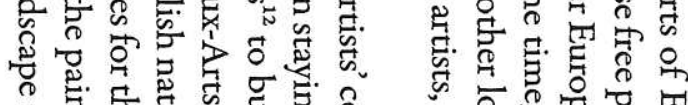

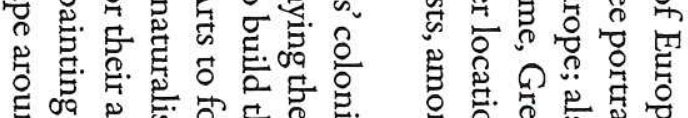

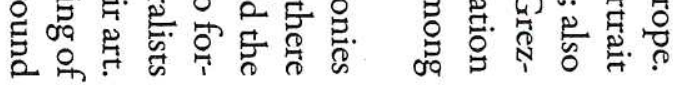

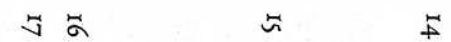

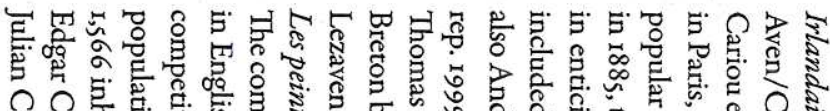

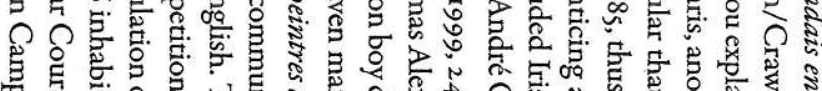

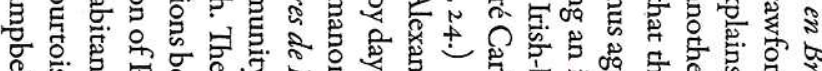

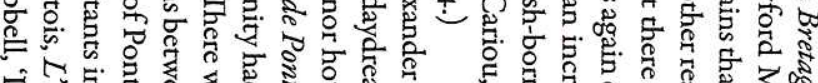

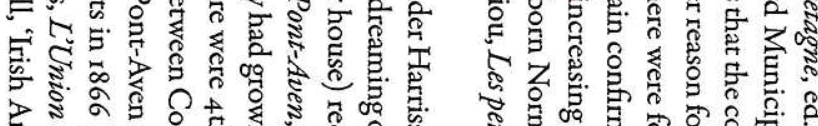
द.

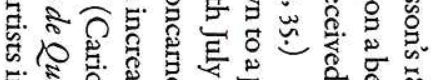

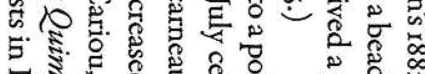

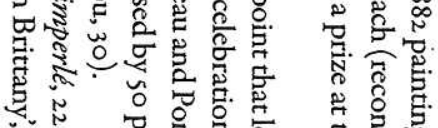

i.

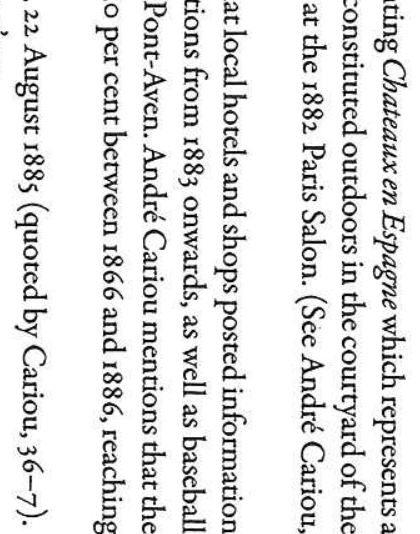

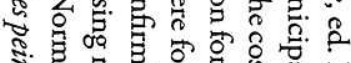

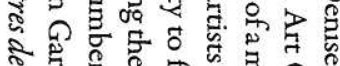

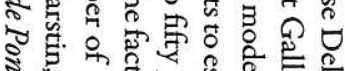

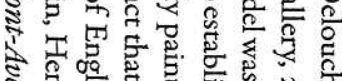

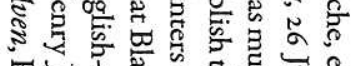

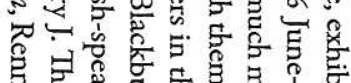

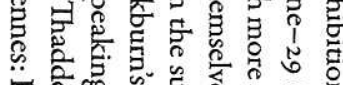

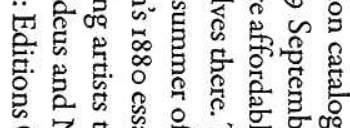

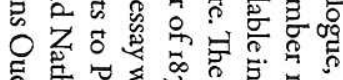

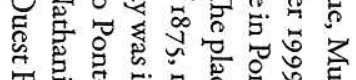

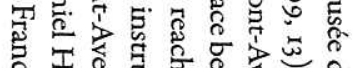

గी

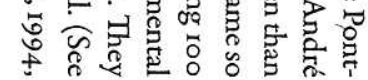

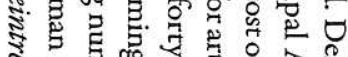

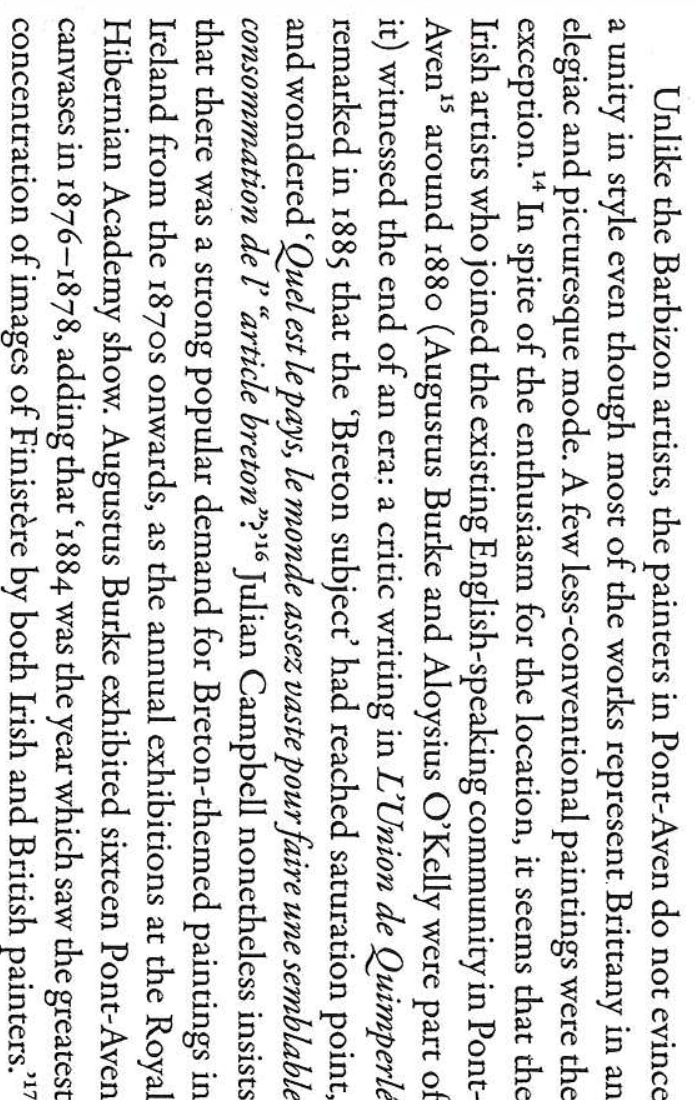


$\check{0} \quad \check{\infty}$

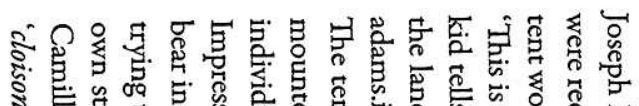

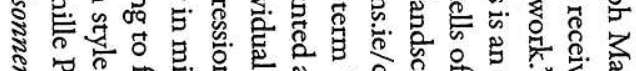

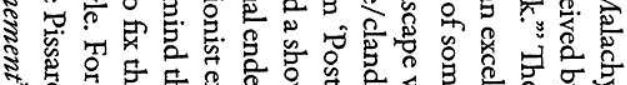

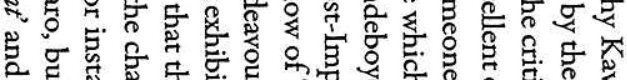

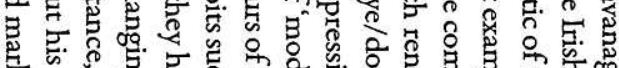

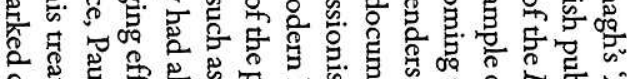

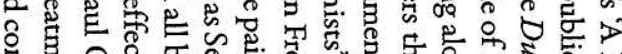

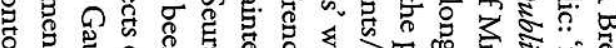

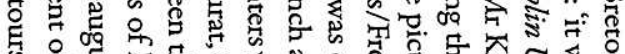

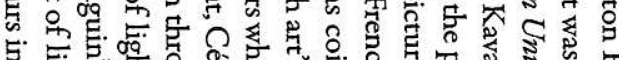

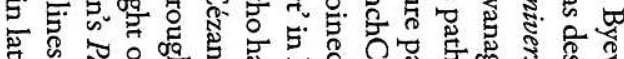

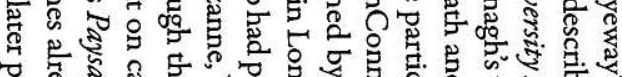

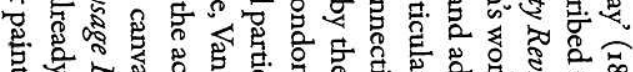

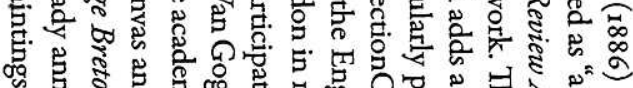

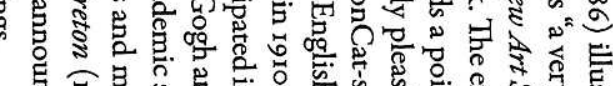

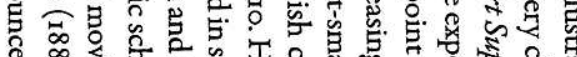

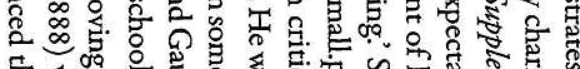

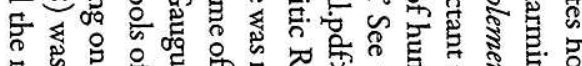

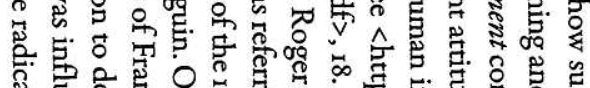

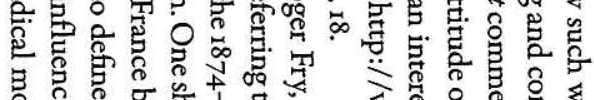

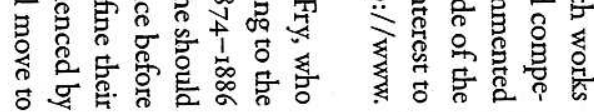

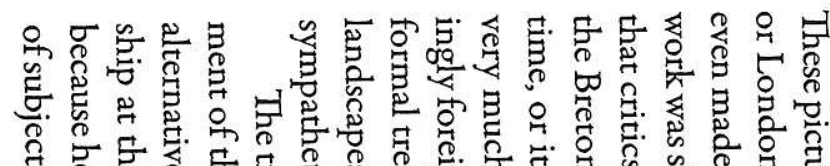
के द्व

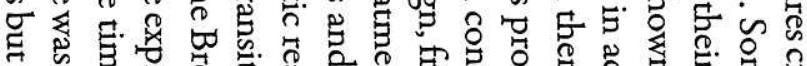

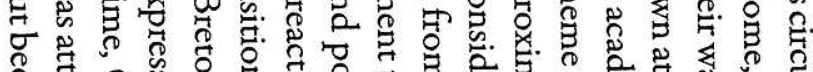

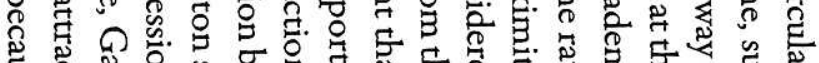

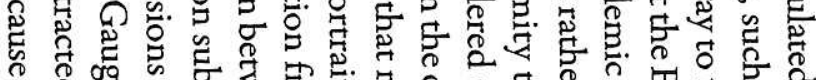

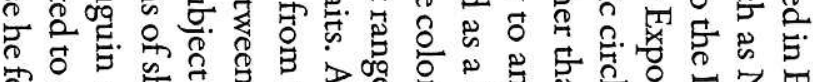

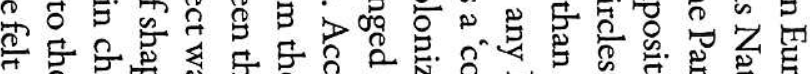

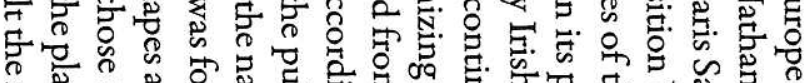

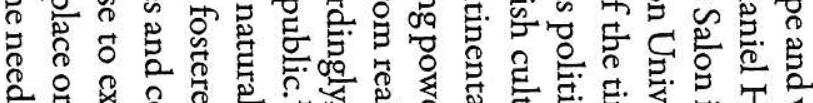

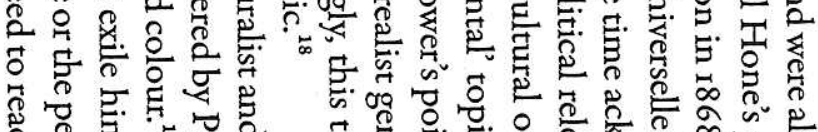

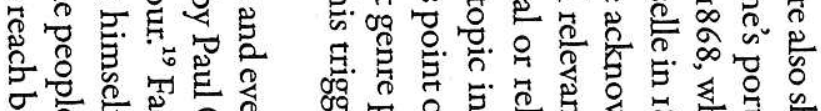

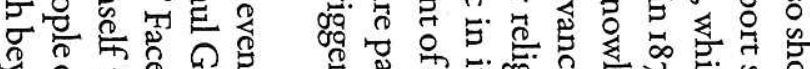

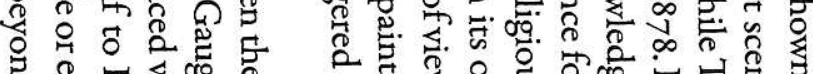

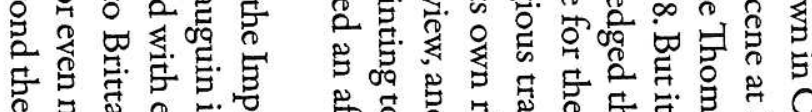

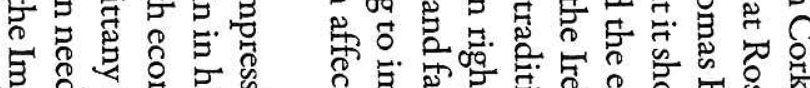

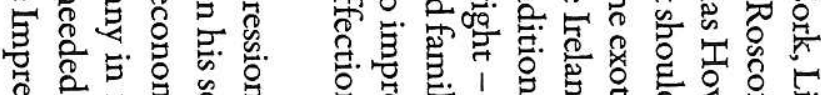

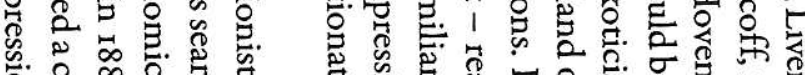

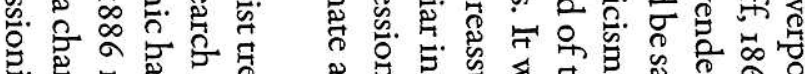

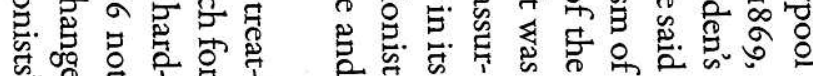

ก

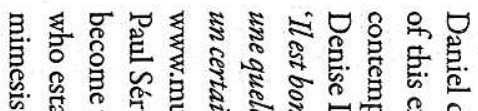

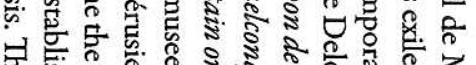
के

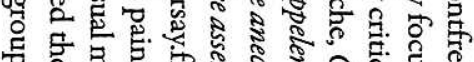

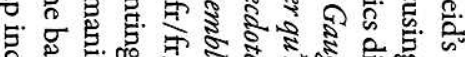

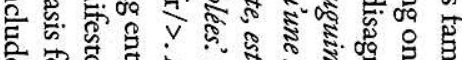

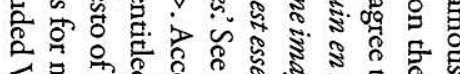

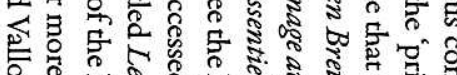

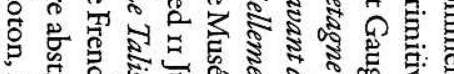

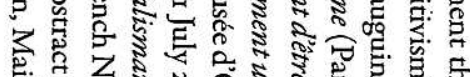

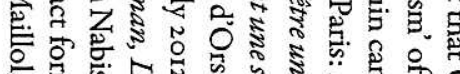

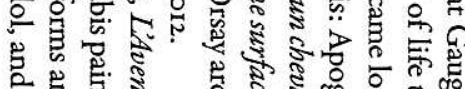
造费

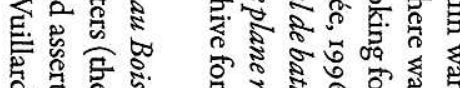

की

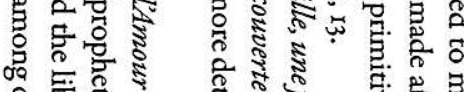

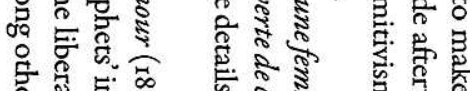

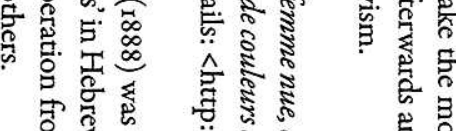

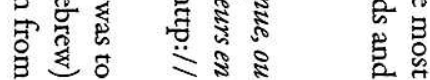

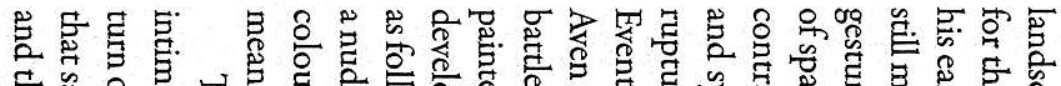

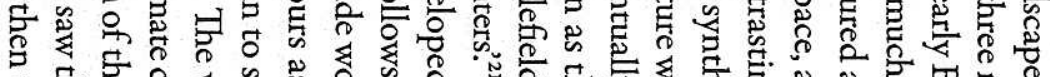

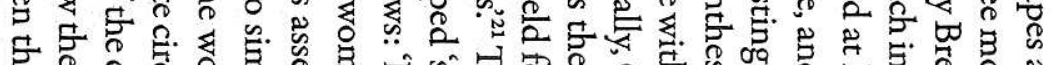

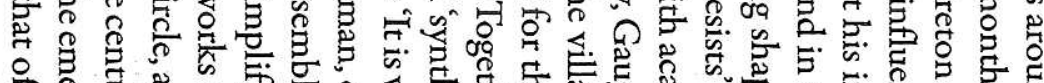

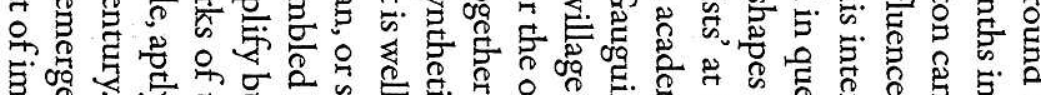

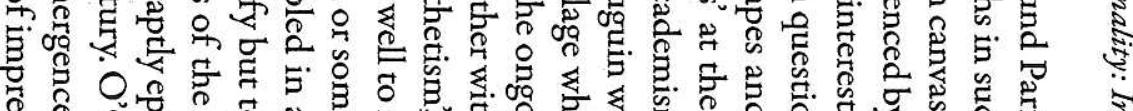

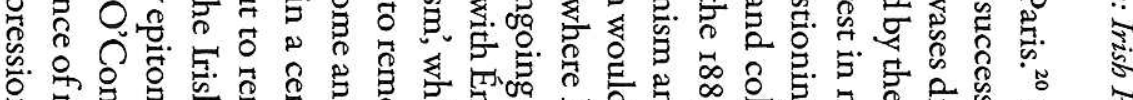

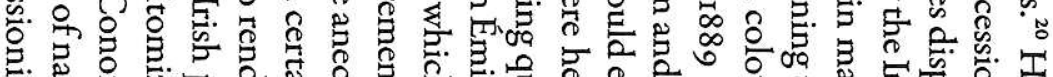

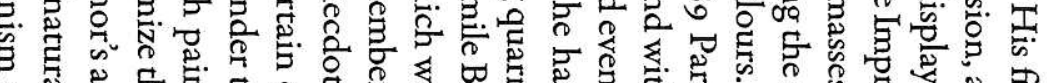

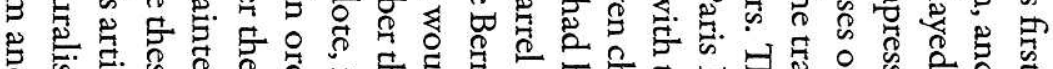

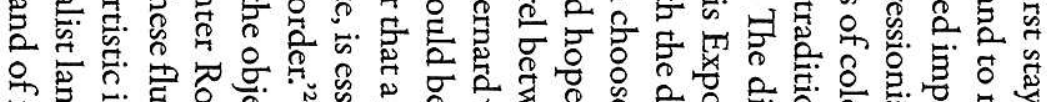

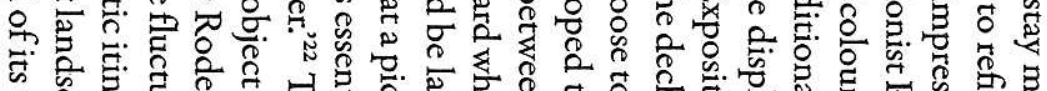
寜. ก. 焉.

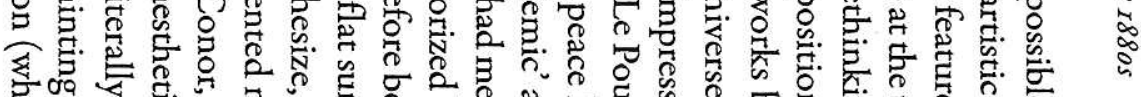

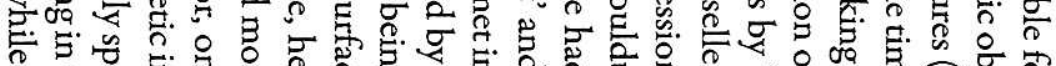

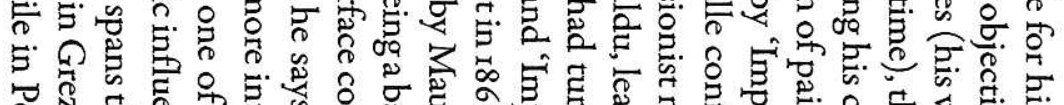

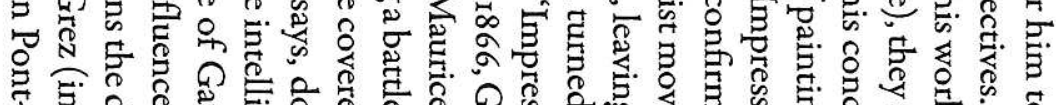

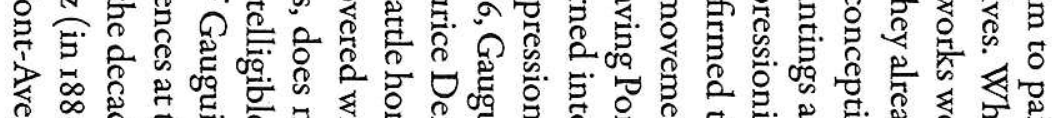

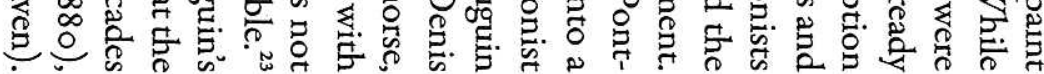

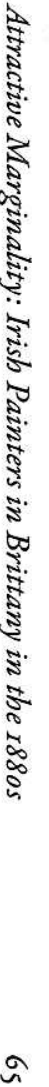




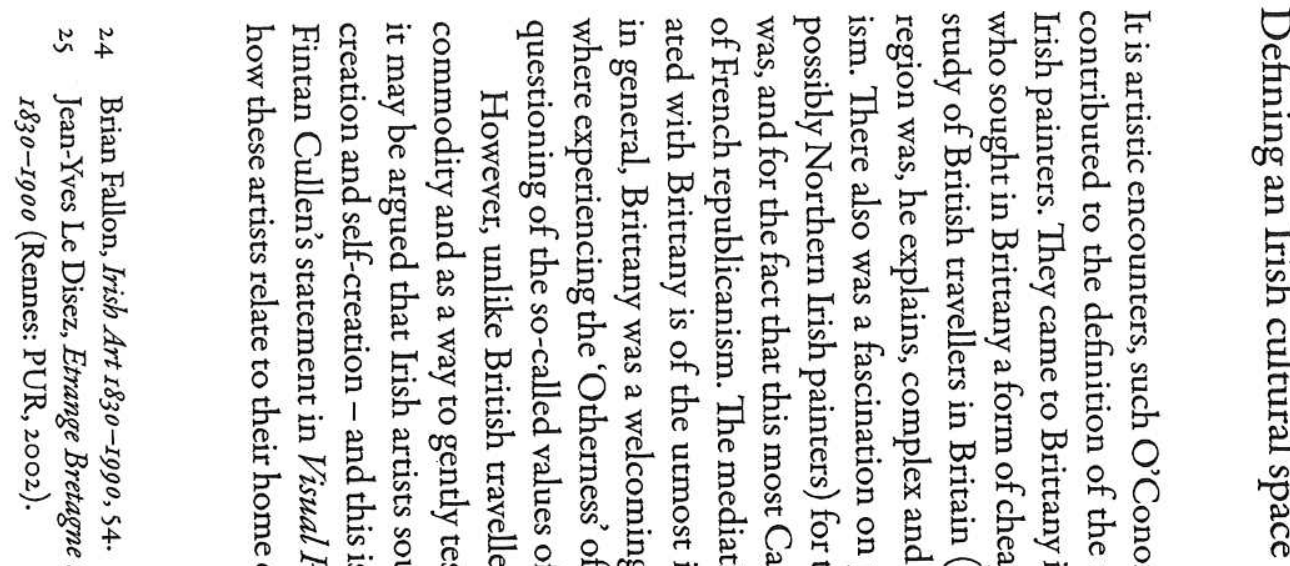

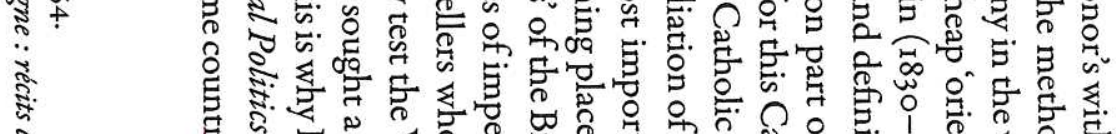

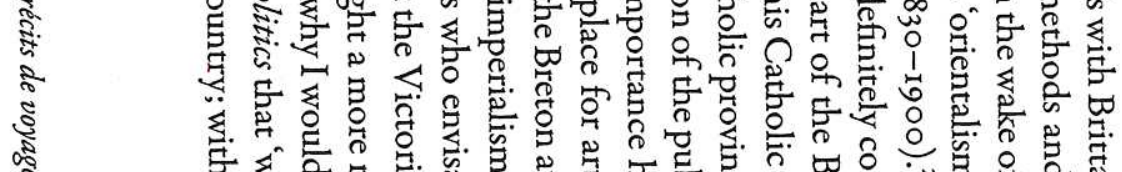

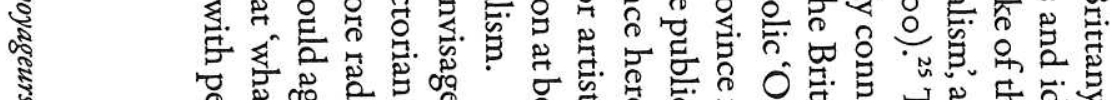

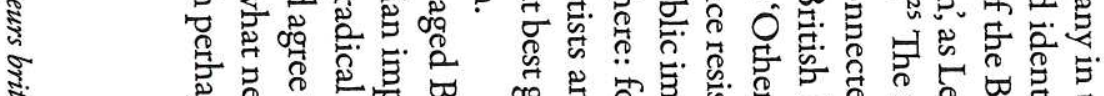

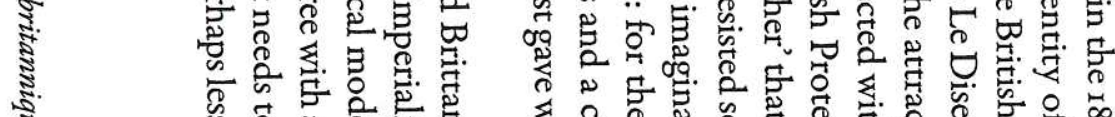

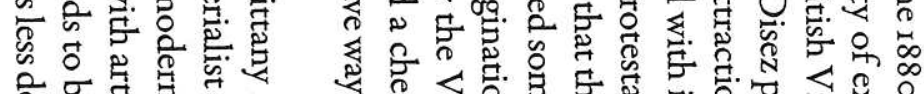

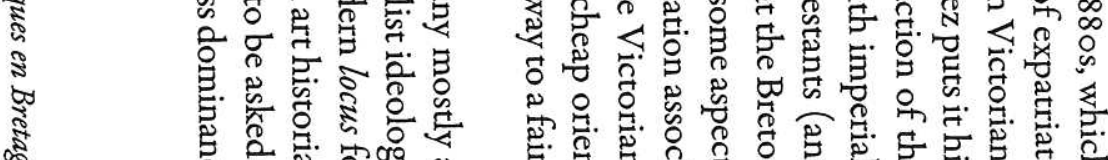

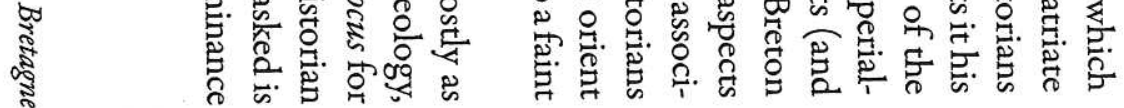

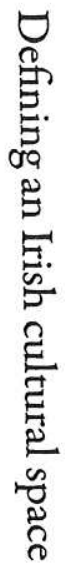

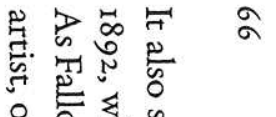

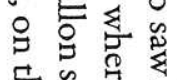

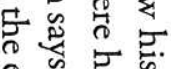

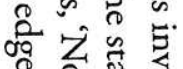

क्वे

定层令

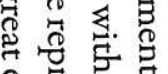

究

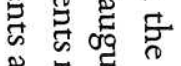

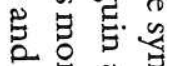

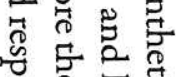

융ㄹ.

寈虽实

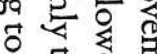

둥

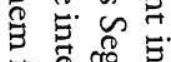

क赵总罗.

.

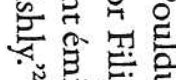

曲. 宊

జ

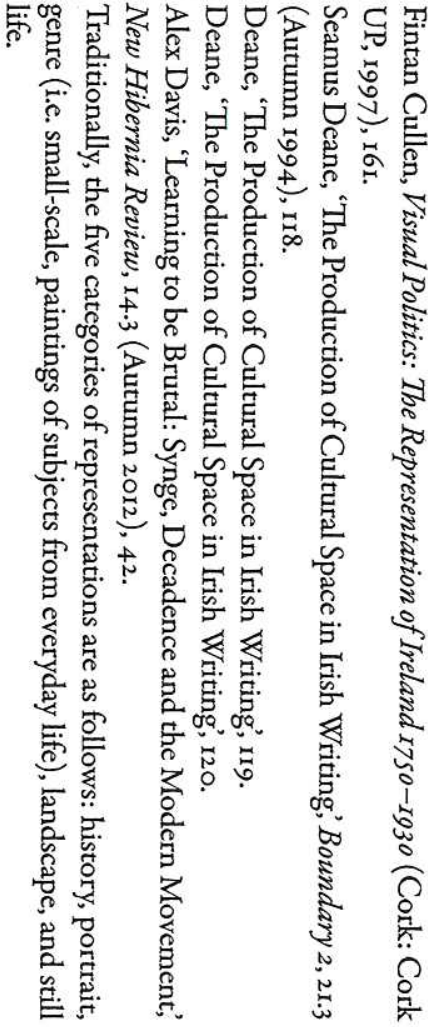

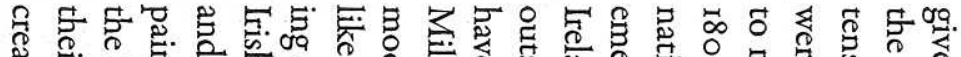

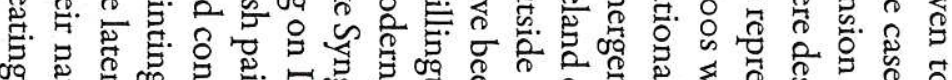

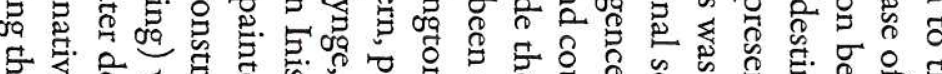

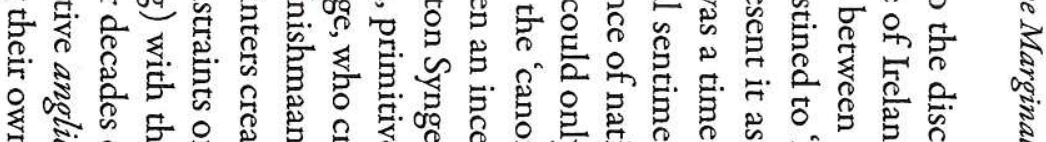

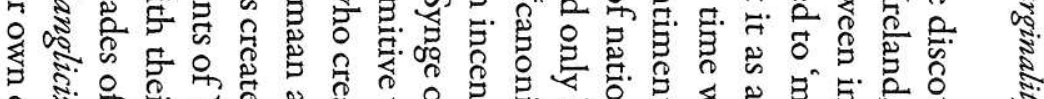

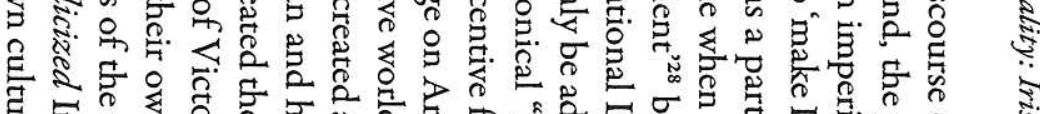

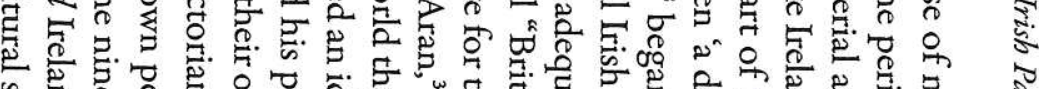

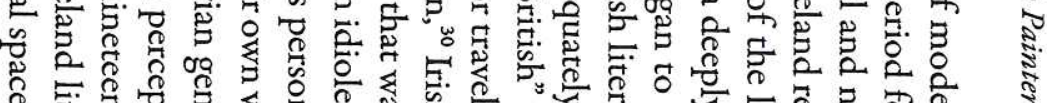

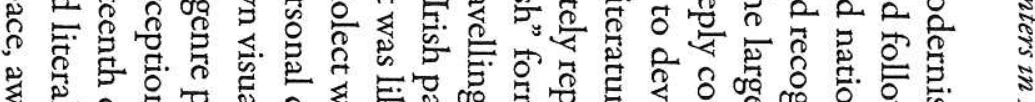

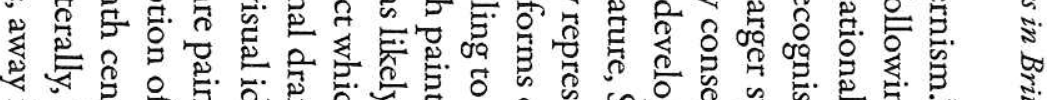

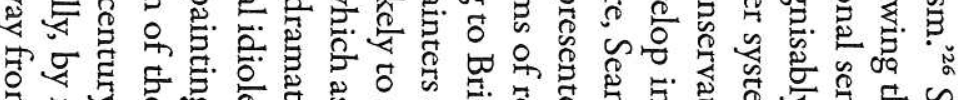

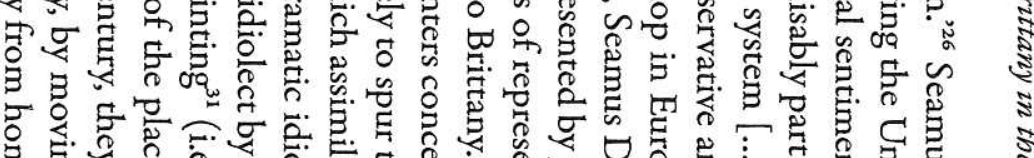

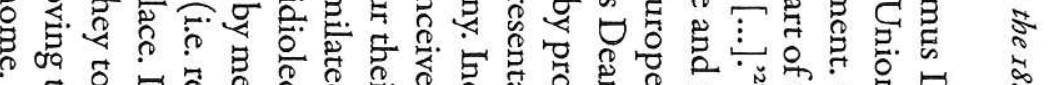
o $\begin{gathered}0.70 \\ 0\end{gathered}$

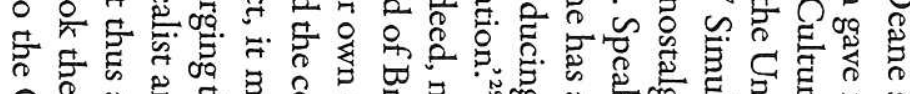

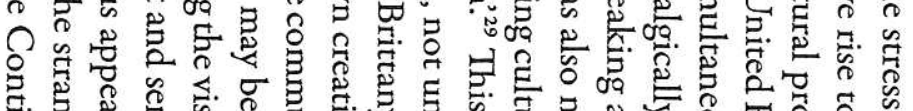

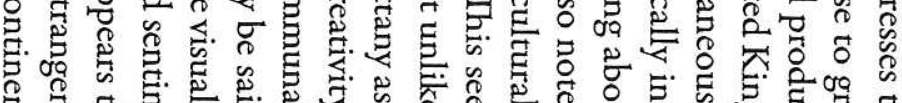

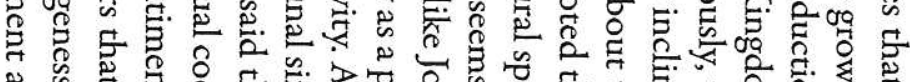

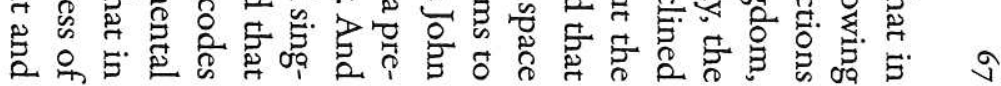


$\stackrel{w}{w}$

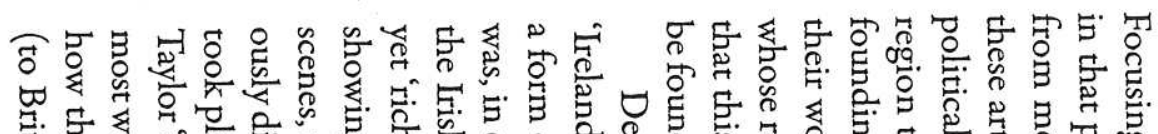

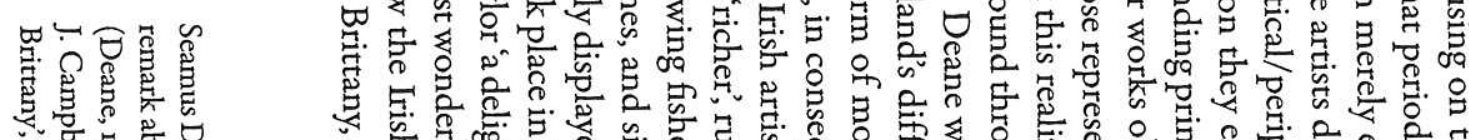

w

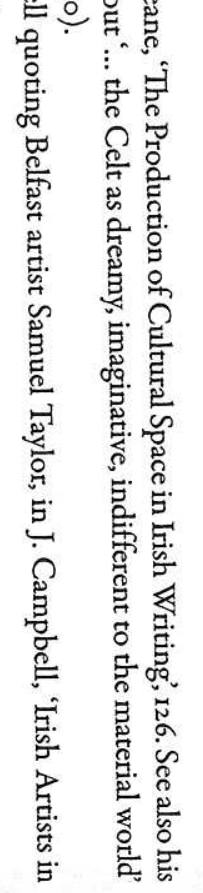

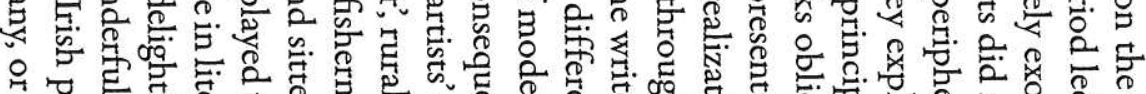

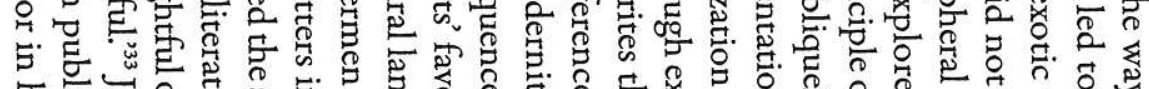

它

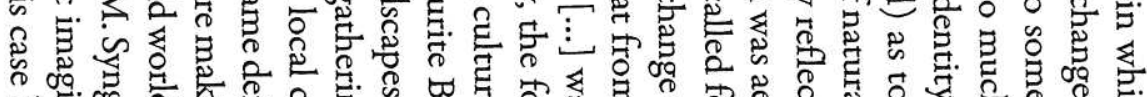

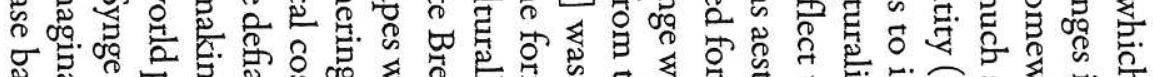

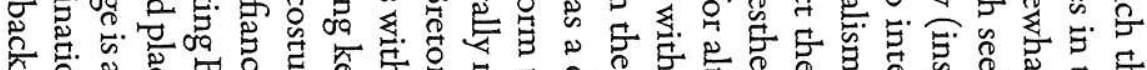

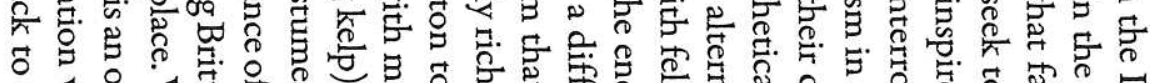

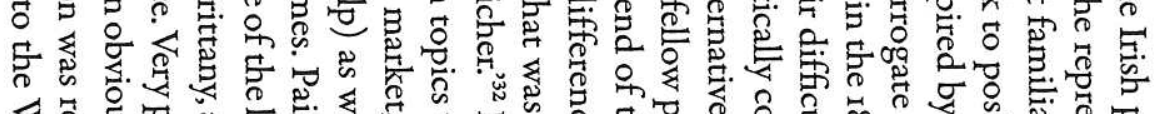

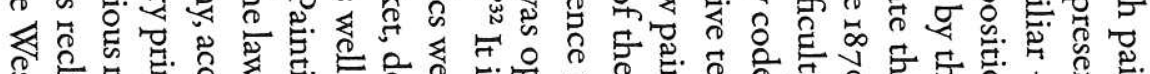

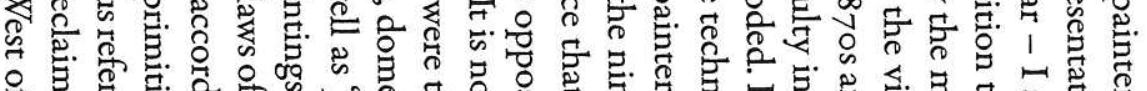

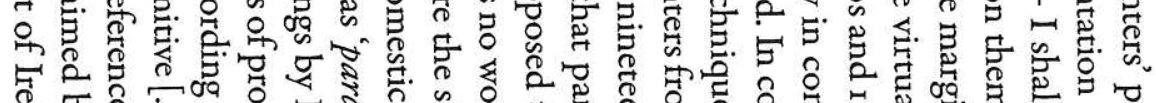

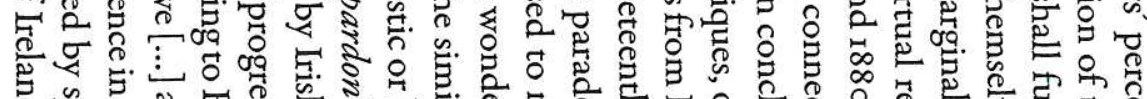

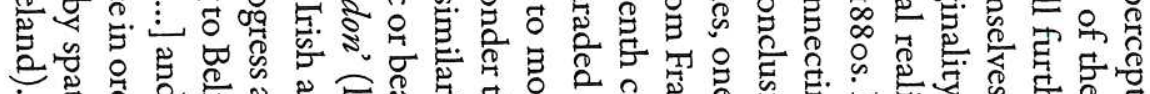

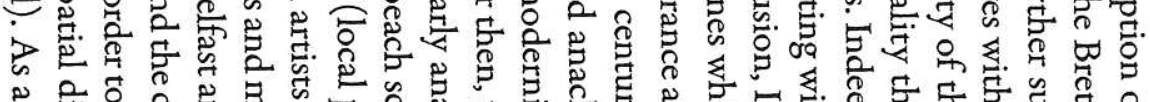

等

T्ञ

$\infty$

ช్̂ิ

.

芴.

\%

宽

必

总:

ڤ.

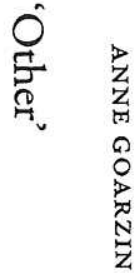

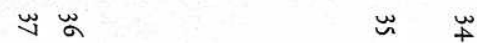

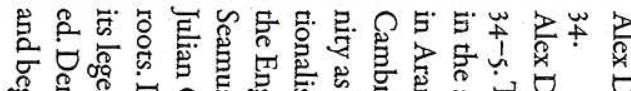

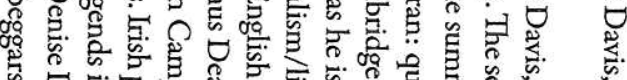

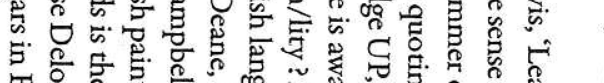

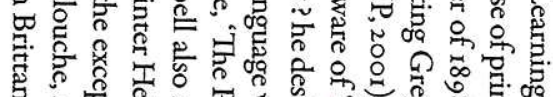

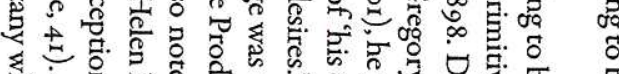

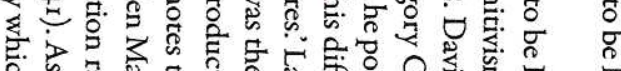

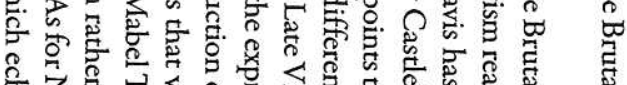

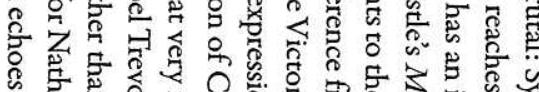

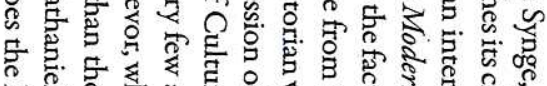

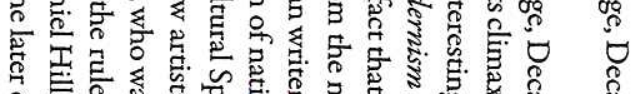
万ิ

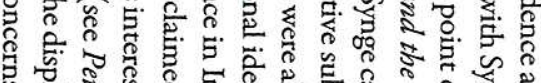

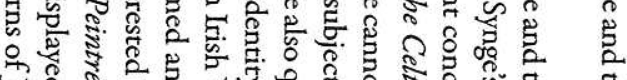

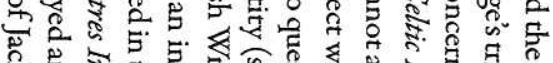

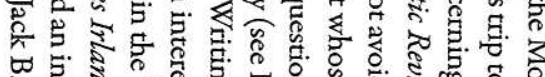
क阝

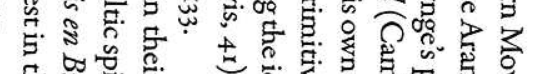

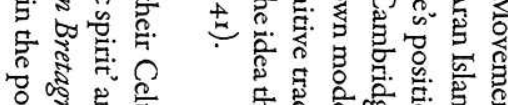
गई

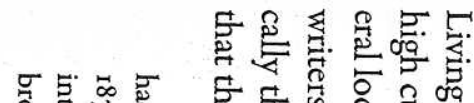

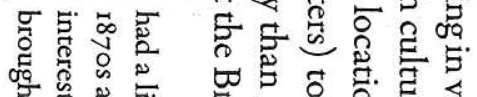

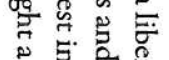
造高蛋

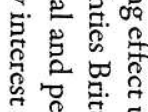

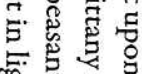
嵒它客 है듀.

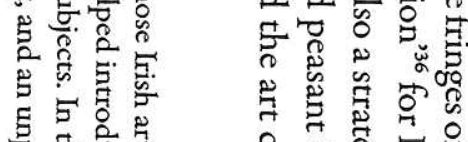
흉

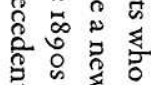
莡范茟 若起黄 8 ॠ

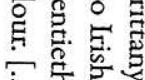
至合落 它吉

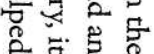

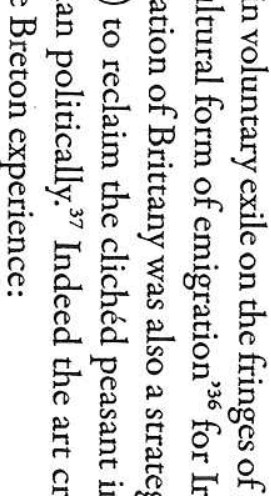

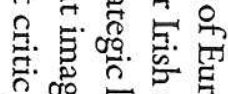

웡

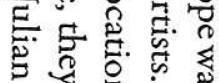

مि क्षे क्ष

氜 今

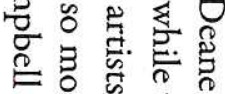

푸융

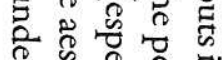

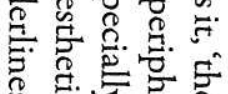

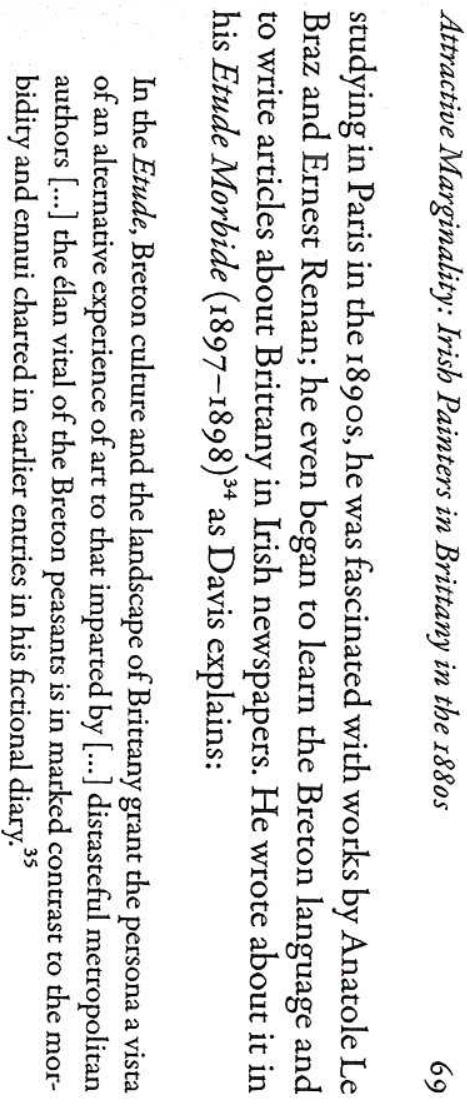


o

$w_{0} w_{\infty}$

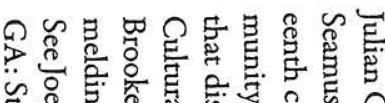

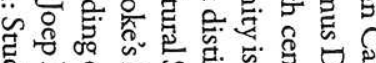

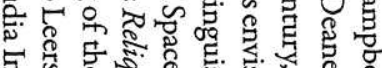
可窎

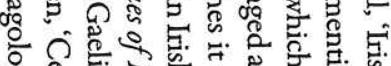

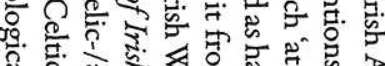
误.

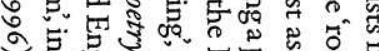

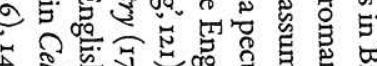
专.

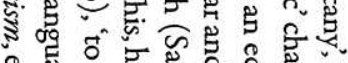

คo

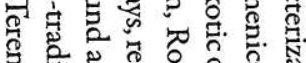

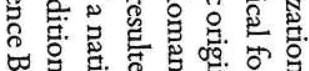

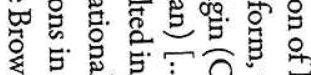

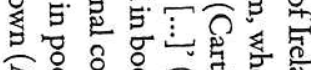

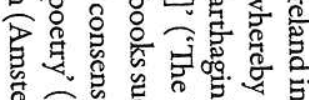

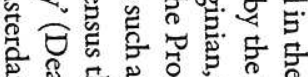

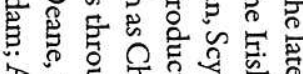

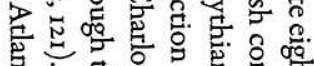

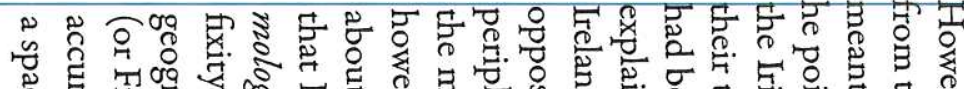

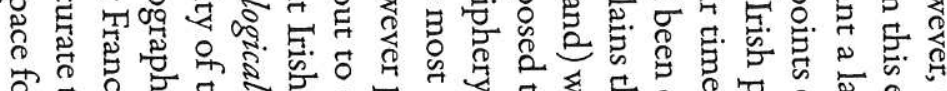
क्ष 0 .

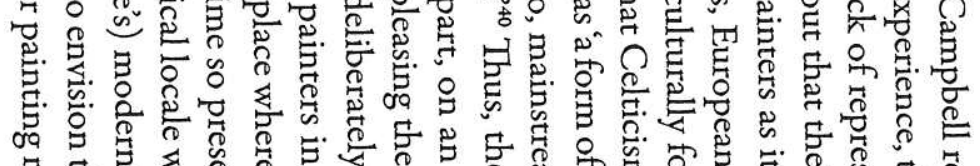

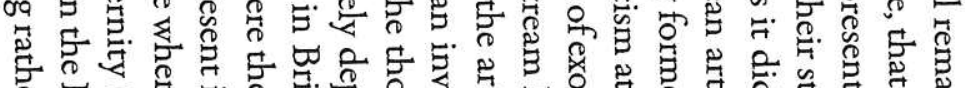

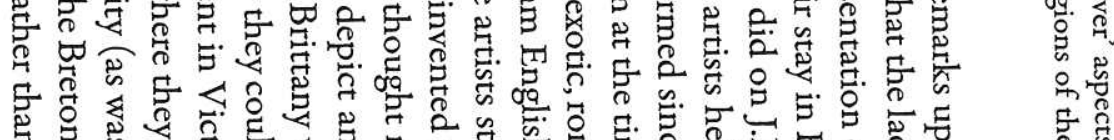

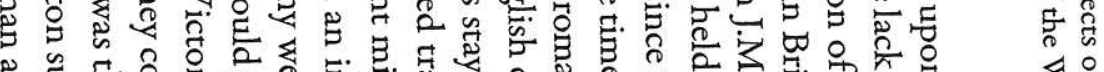

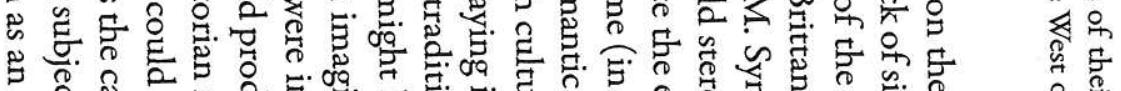

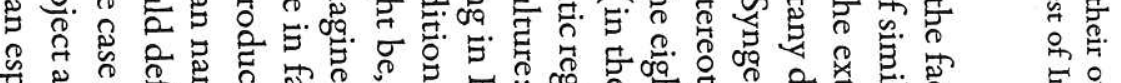

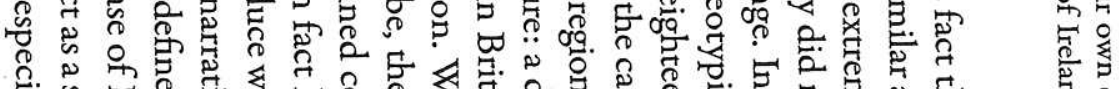

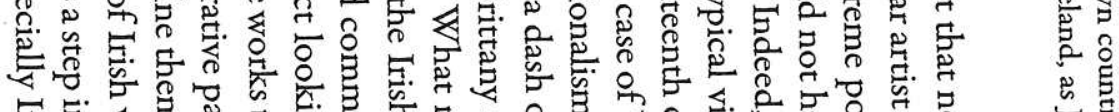

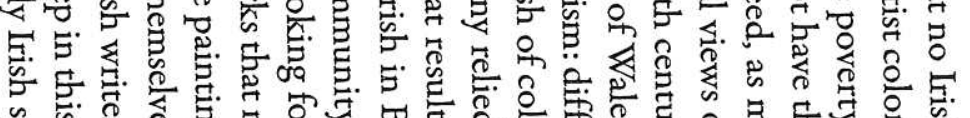

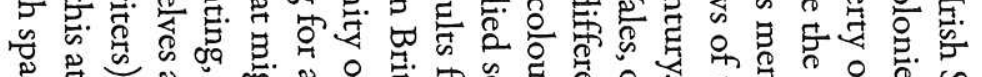

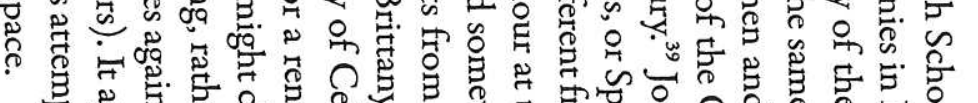

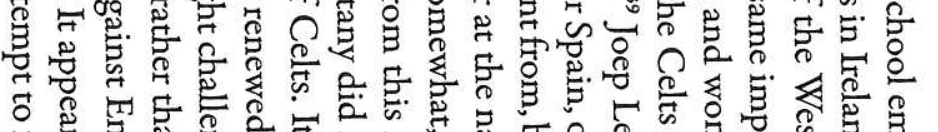

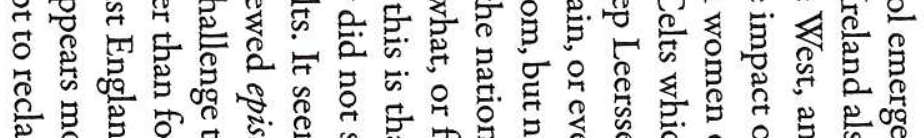

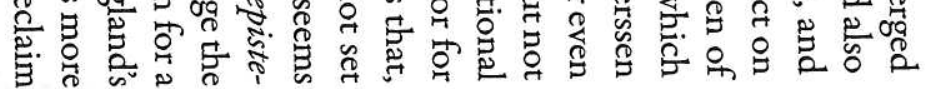

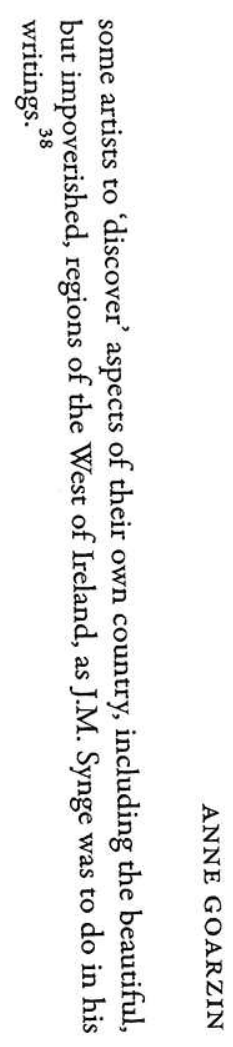

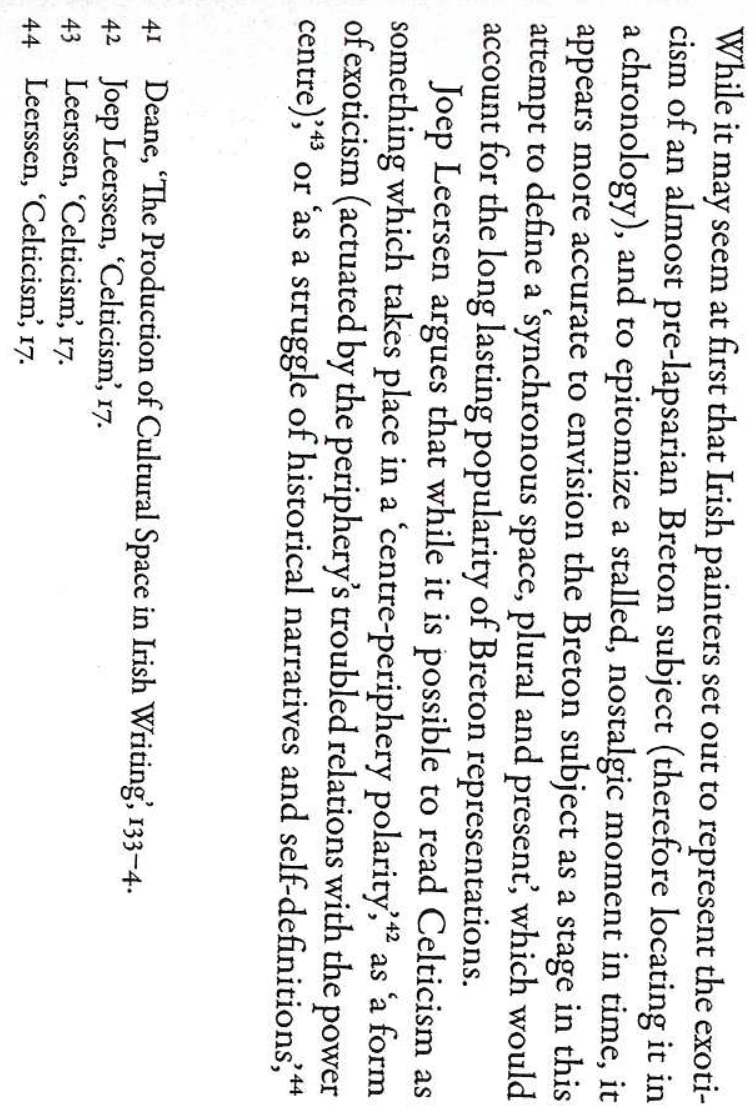

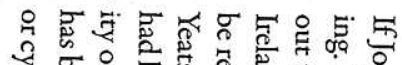

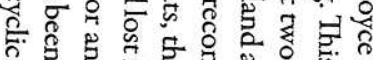

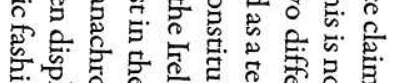

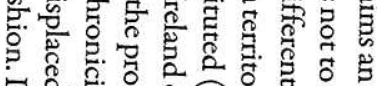

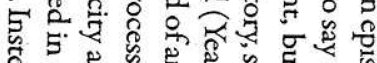

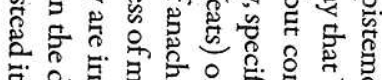
त.

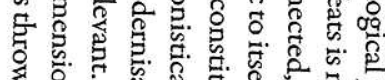

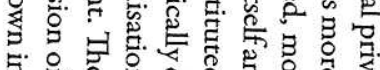

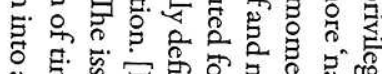

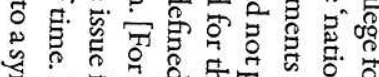

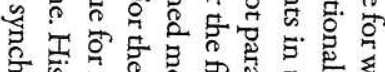

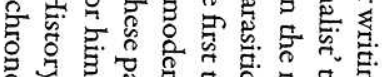

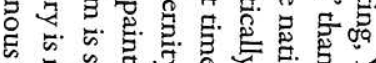

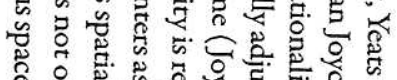
क्रे

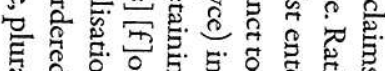

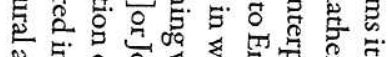

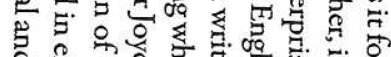

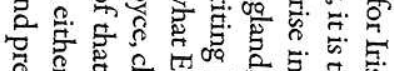

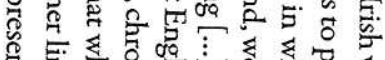

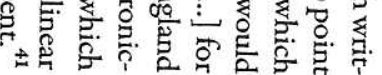

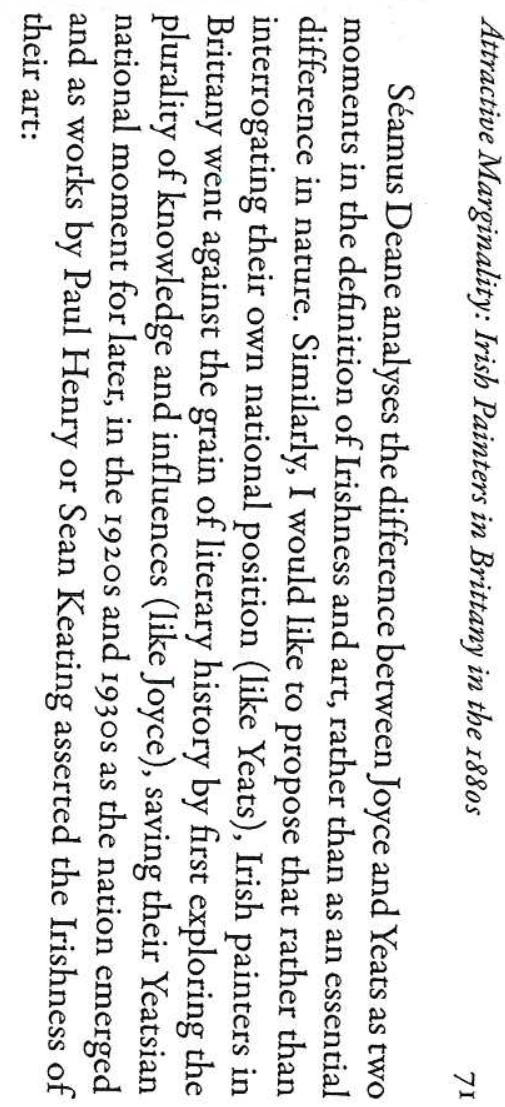




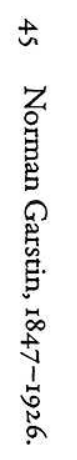

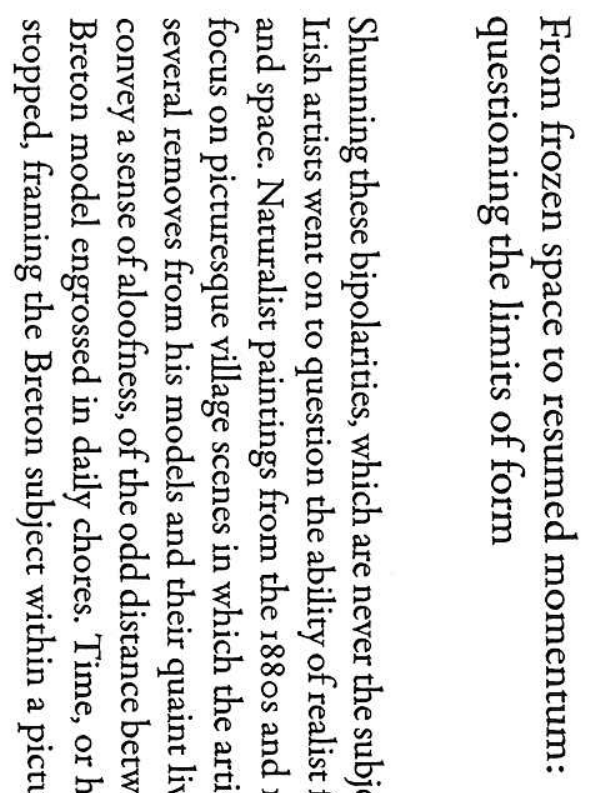

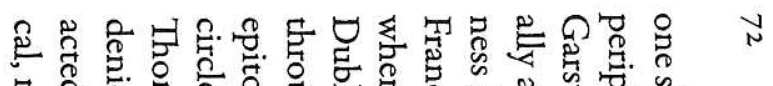

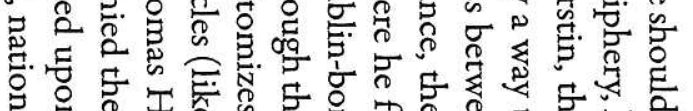

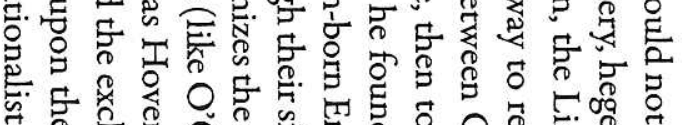

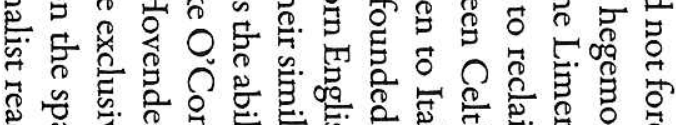

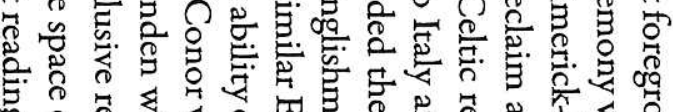

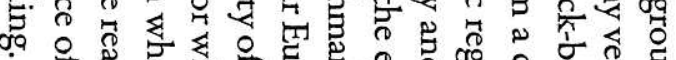

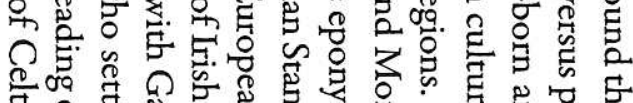

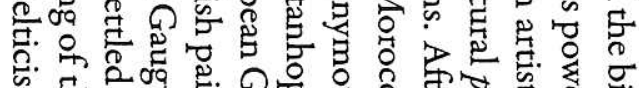

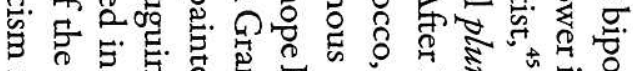

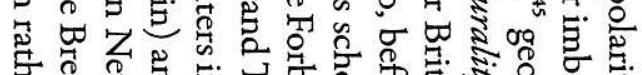
क्ष

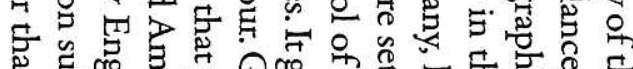
릉.

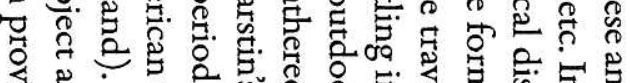

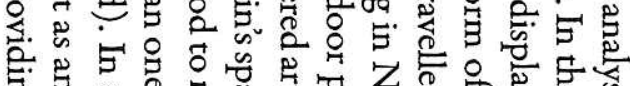

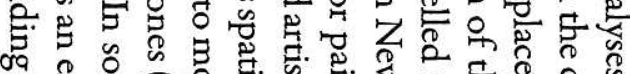
等.

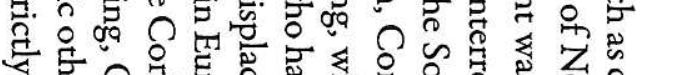

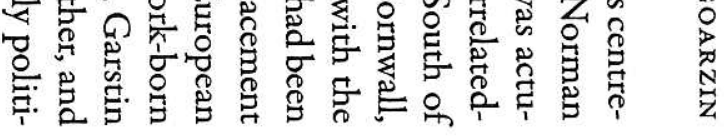

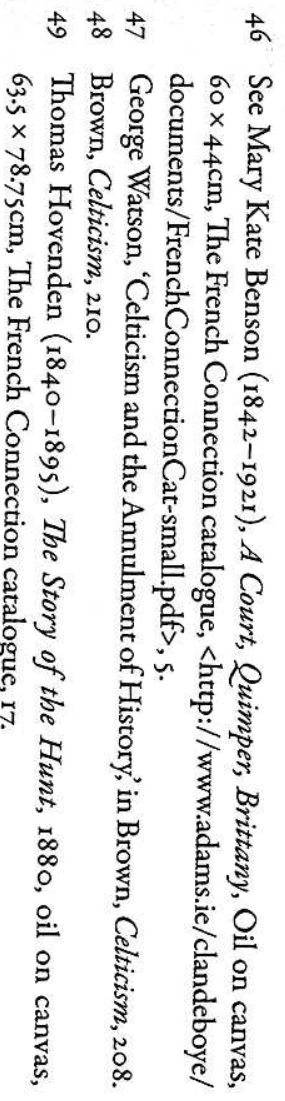

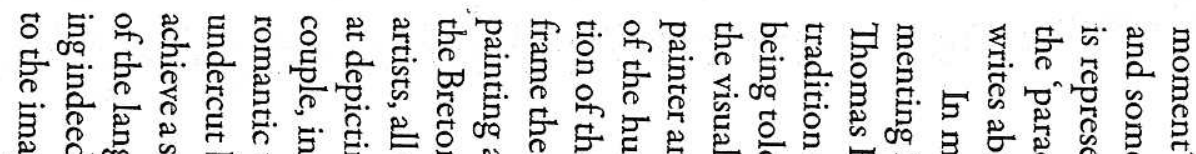

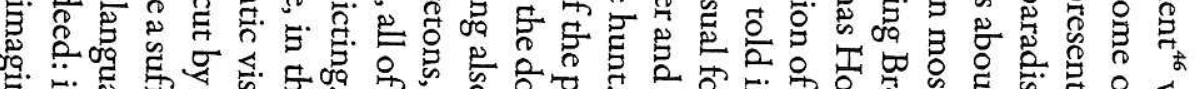

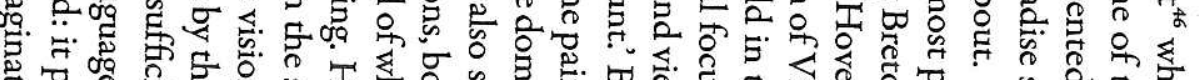

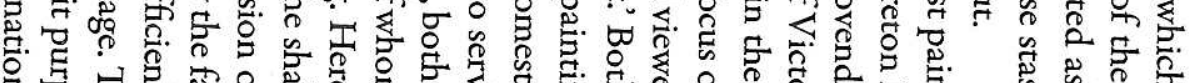

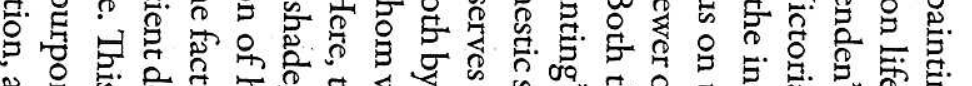

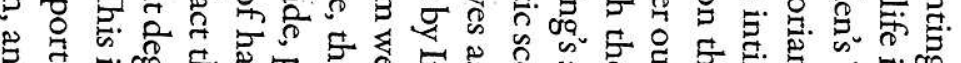

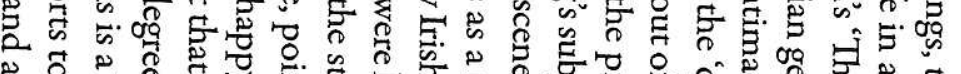

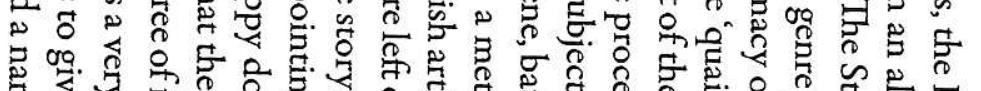

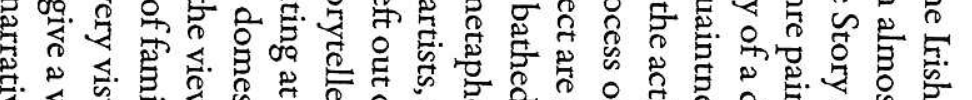
.

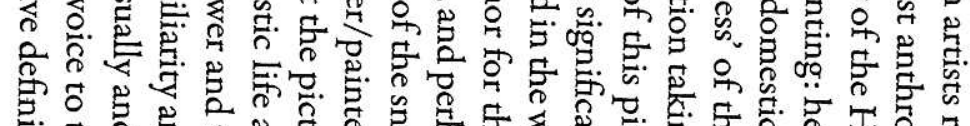

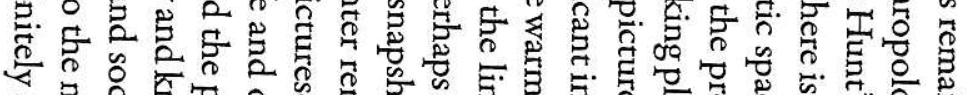

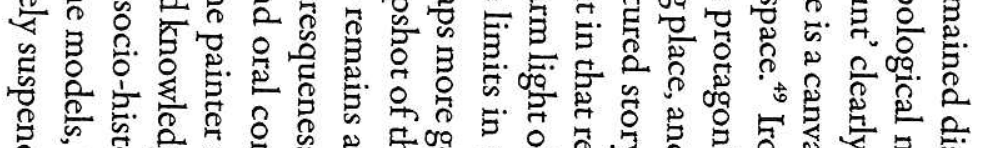

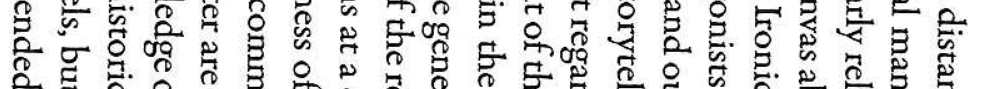

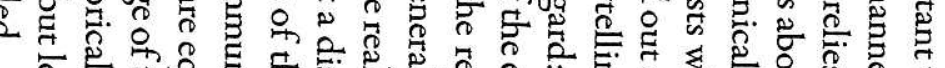

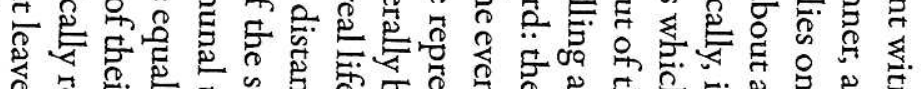

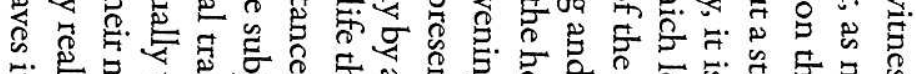

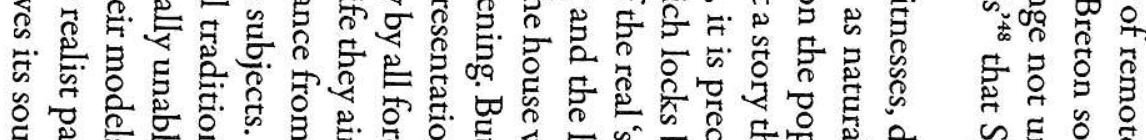

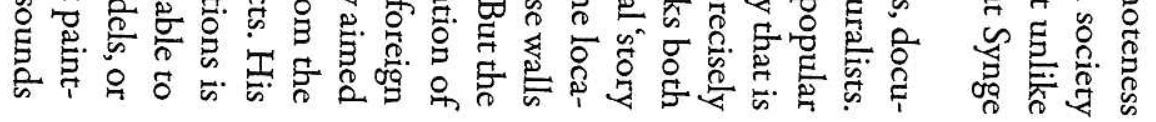


背

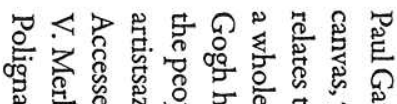
กั

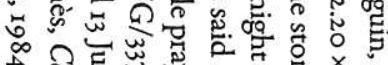

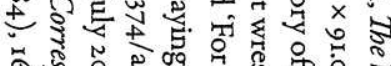

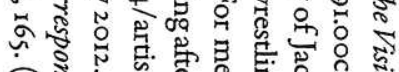

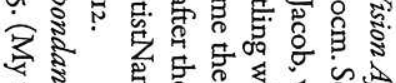

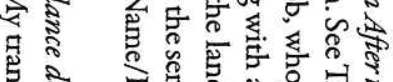

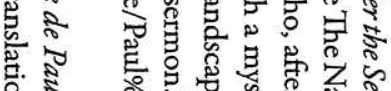

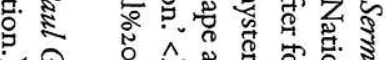
ई ㄴ.

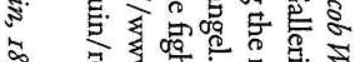

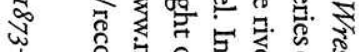

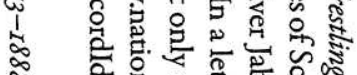

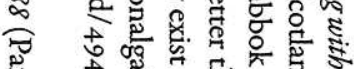

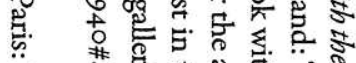

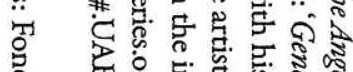

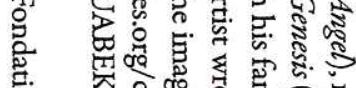

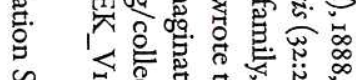

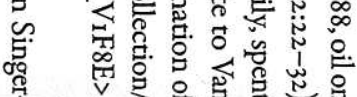

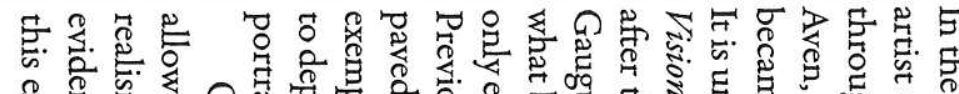

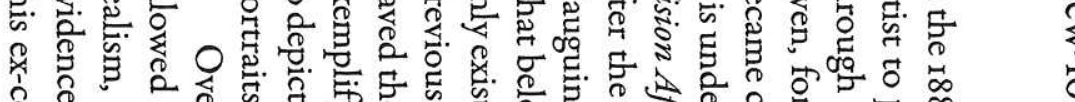

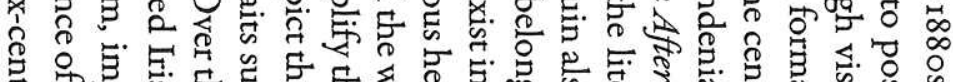

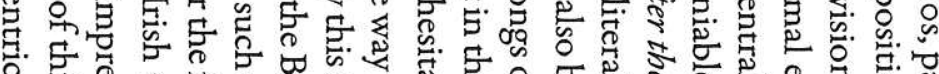

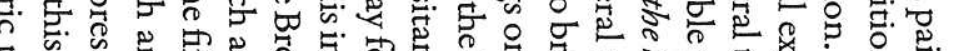

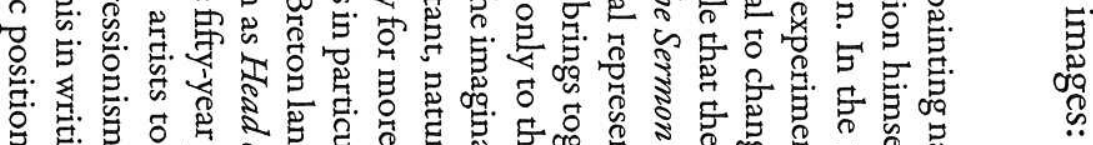

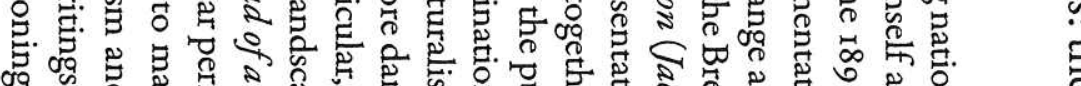

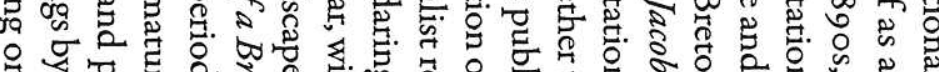

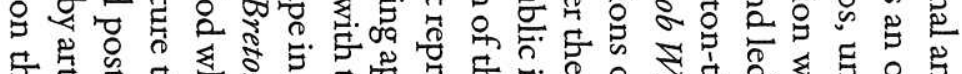

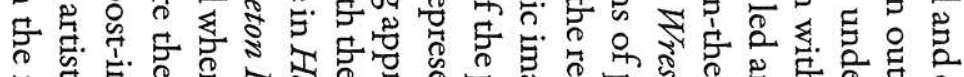

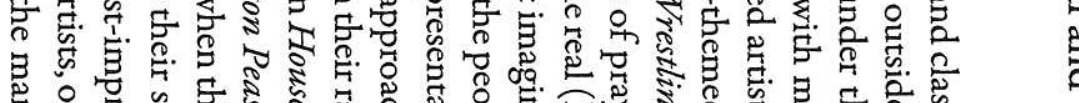

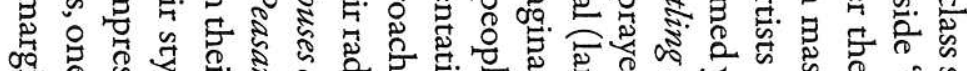

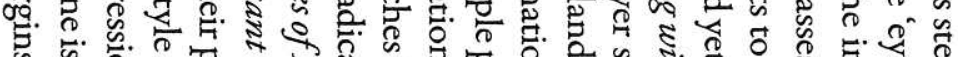

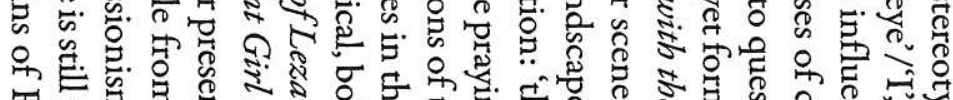

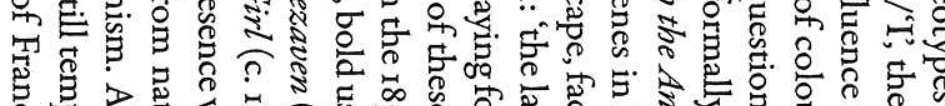

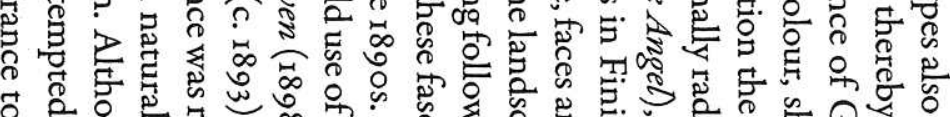

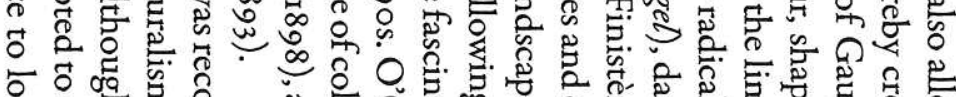
०

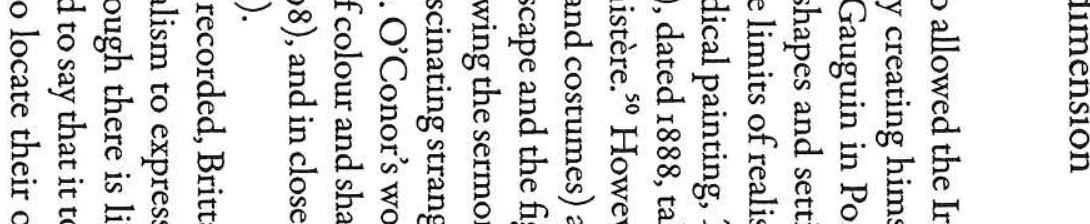

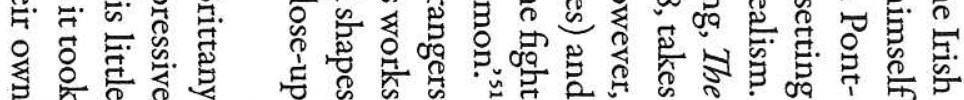

$\breve{+}$

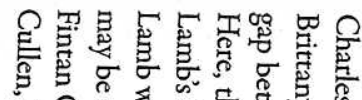

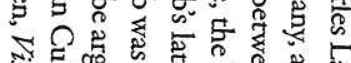

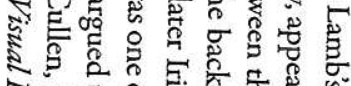

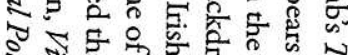

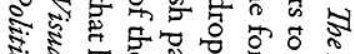

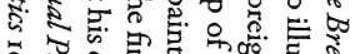

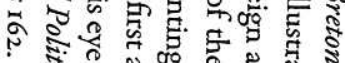

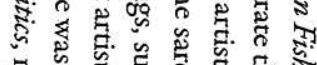
ॠ 5.

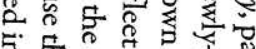
한.

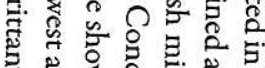

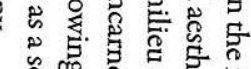
के है ¿ 范吉.

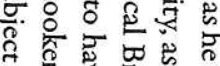

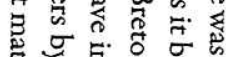
$\rightleftarrows$ অ.

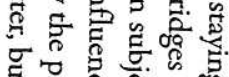
可.

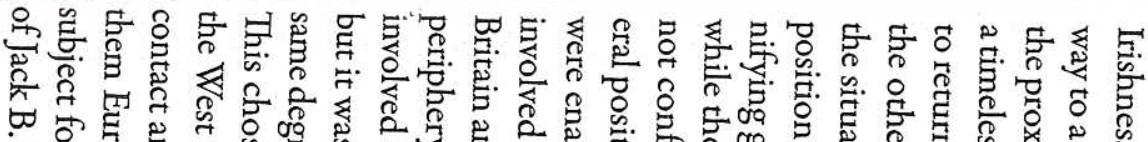

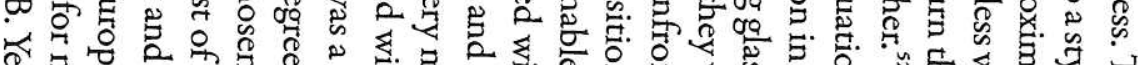

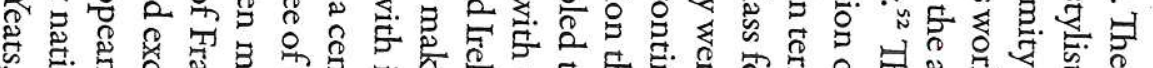

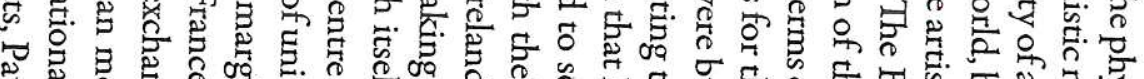

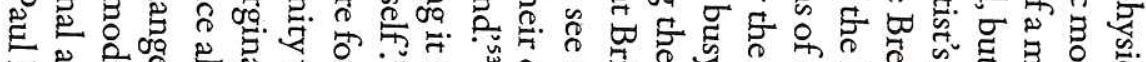

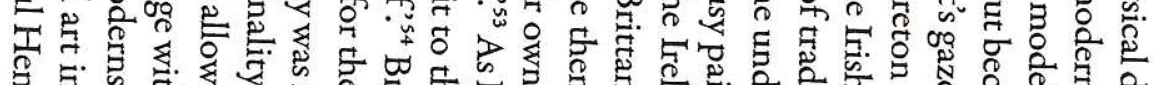

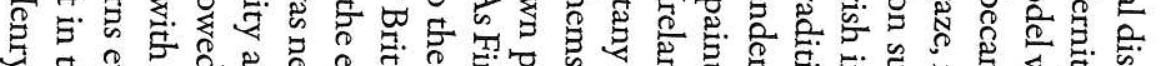
○

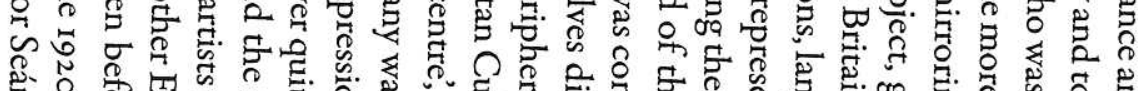

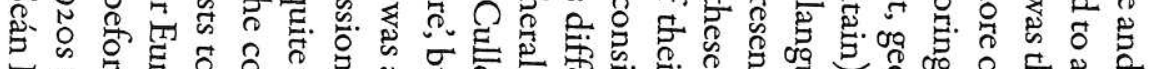
不

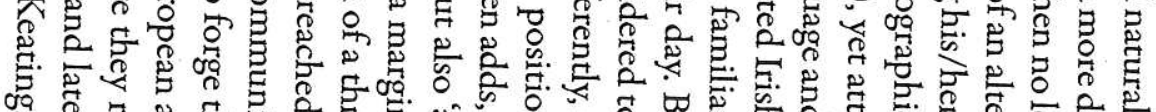

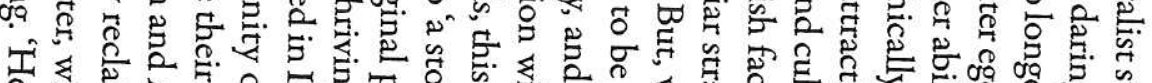

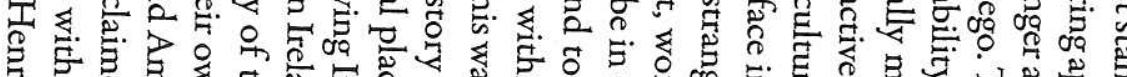

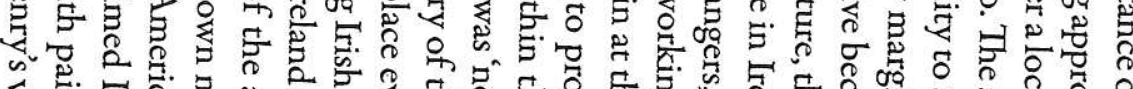

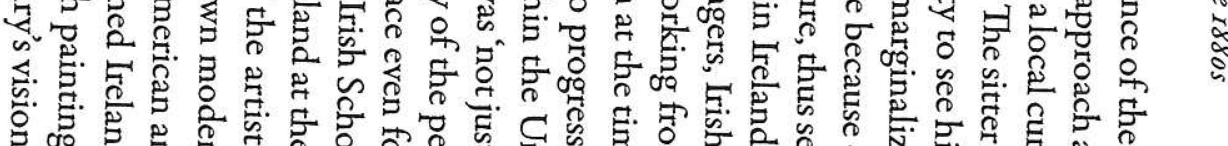

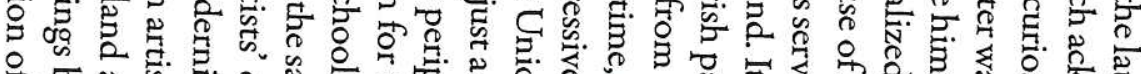

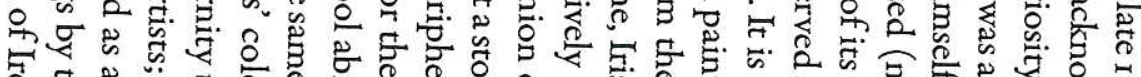

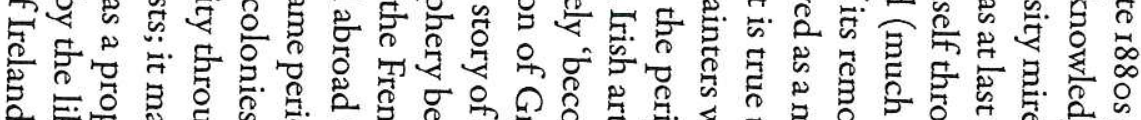

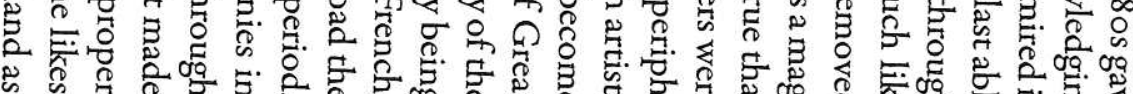

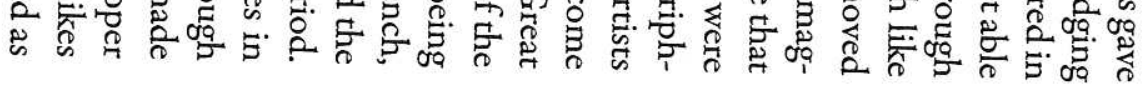

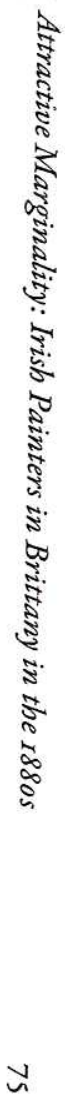



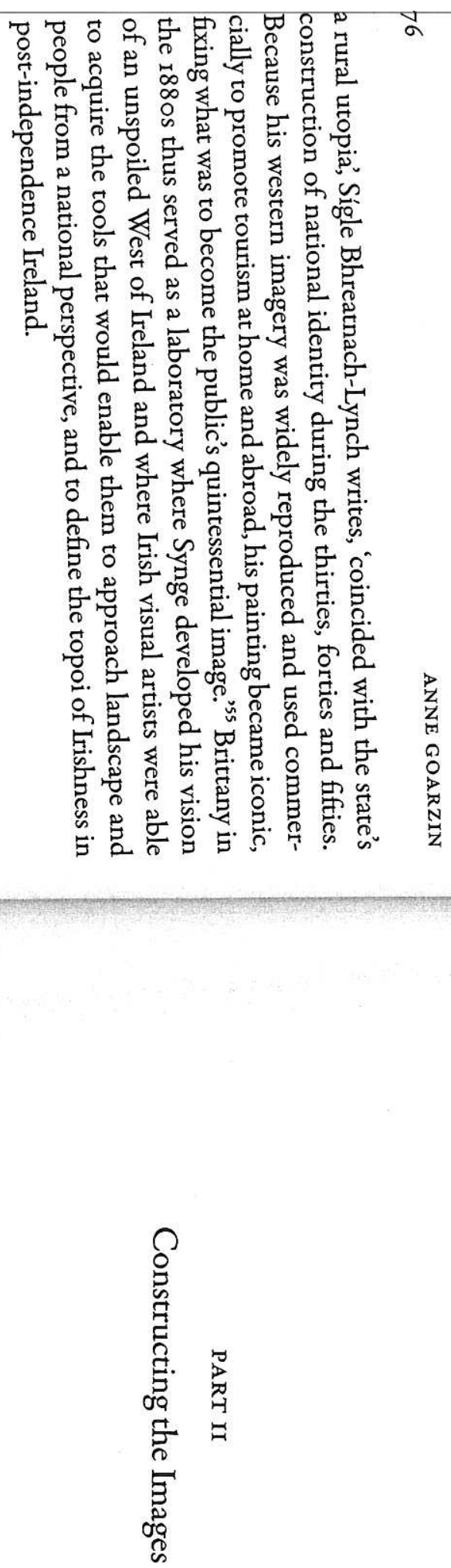